\title{
Genotoxic stress triggers the activation of IRE1 $\alpha$-dependent RNA decay to modulate the DNA damage response
}

Estefanie Dufey 1,2,3, José Manuel Bravo-San Pedro4,5, Cristian Eggers ${ }^{6,7}$, Matías González-Quiroz (iD) 1,2,3,8,9, Hery Urra1,2,3, Alfredo I. Sagredo1,2,3, Denisse Sepulveda1,2,3, Philippe Pihán 1,2,3, Amado Carreras-Sureda 1,2,3, Younis Hazari ${ }^{1,2,3}$, Eduardo A. Sagredo ${ }^{10}$, Daniela Gutierrez ${ }^{11}$, Cristian Valls ${ }^{11}$, Alexandra Papaioannou (i) ${ }^{8,9}$, Diego Acosta-Alvear ${ }^{12,13,14}$, Gisela Campos ${ }^{15}$, Pedro M. Domingos (10) ${ }^{16}$, Rémy Pedeux ${ }^{8,9}$, Eric Chevet (D) ${ }^{8,9}$, Alejandra Alvarez ${ }^{11}$, Patricio Godoy ${ }^{15}$, Peter Walter (1) ${ }^{12,13}$, Alvaro Glavic 6,7 , Guido Kroemer (1) 4,5,17,18,19 \& Claudio Hetz (10) 1,2,3,20凶

The molecular connections between homeostatic systems that maintain both genome integrity and proteostasis are poorly understood. Here we identify the selective activation of the unfolded protein response transducer IRE $\alpha$ under genotoxic stress to modulate repair programs and sustain cell survival. DNA damage engages IRE1 $\alpha$ signaling in the absence of an endoplasmic reticulum (ER) stress signature, leading to the exclusive activation of regulated IRE1 $\alpha$-dependent decay (RIDD) without activating its canonical output mediated by the transcription factor XBP1. IRE1 $\alpha$ endoribonuclease activity controls the stability of mRNAs involved in the DNA damage response, impacting DNA repair, cell cycle arrest and apoptosis. The activation of the c-Abl kinase by DNA damage triggers the oligomerization of IRE1 $\alpha$ to catalyze RIDD. The protective role of IRE1 $\alpha$ under genotoxic stress is conserved in fly and mouse. Altogether, our results uncover an important intersection between the molecular pathways that sustain genome stability and proteostasis.

\footnotetext{
${ }^{1}$ Biomedical Neuroscience Institute (BNI), Faculty of Medicine, University of Chile, Santiago, Chile. ${ }^{2}$ Center for Geroscience, Brain Health and Metabolism (GERO), Santiago, Chile. ${ }^{3}$ Program of Cellular and Molecular Biology, Institute of Biomedical Sciences, University of Chile, Santiago, Chile. ${ }^{4}$ Centre de Recherche des Cordeliers, Equipe labellisée par la Ligue contre le cancer, Inserm U1138, Université de Paris, Sorbonne Université, Paris, France.

${ }^{5}$ Metabolomics and Cell Biology Platforms, Gustave Roussy Cancer Campus, Villejuif, France. ${ }^{6}$ Department of Biology, Faculty of Sciences, University of Chile, Santiago, Chile. ${ }^{7}$ Center for Genome Regulation, Faculty of Sciences, University of Chile, Santiago, Chile. ${ }^{8}$ Proteostasis \& Cancer Team, INSERM U1242, University of Rennes 1, Rennes, France. ${ }^{9}$ Centre de Lutte contre le Cancer Eugène Marquis, Rennes, France. ${ }^{10}$ Department of Molecular Biosciences, The Wenner-Gren Institute, Stockholm University, Svante Arrheniusväg 20C, 10691 Stockholm, Sweden. ${ }^{11}$ Department of Cell \& Molecular Biology, Pontificia Universidad Católica de Chile, 8331010 Santiago, Chile. ${ }^{12}$ Department of Biochemistry and Biophysics, University of California, San Francisco, CA, USA. ${ }^{13}$ Howard Hughes Medical Institute, University of California, San Francisco, San Francisco, CA, USA. ${ }^{14}$ Department of Molecular, Cellular, and Developmental Biology, University of California, Santa Barbara, Santa Barbara, CA 93106, USA. ${ }^{15}$ IfADo-Leibniz Research Centre for Working Environment and Human Factors at the Technical University Dortmund, 44139 Dortmund, Germany. ${ }^{16}$ Instituto de Tecnologia Química e Biológica, Universidade Nova de Lisboa, Av. da República, 2780-157 Oeiras, Portugal. ${ }^{17}$ Pôle de Biologie, Hôpital Européen Georges Pompidou, AP-HP, Paris, France. ${ }^{18}$ Suzhou Institute for Systems Medicine, Chinese Academy of Medical Sciences, Suzhou, China. ${ }^{19}$ Department of Women's and Children's Health, Karolinska Institute, Karolinska University Hospital, Stockholm, Sweden. ${ }^{20}$ The Buck Institute for Research in Aging, Novato, CA 94945, USA. ${ }^{凶}$ email: chetz@med.uchile.cl
} 
T he integrity of the genome is constantly threatened by endogenously produced toxic metabolites, physical, and chemical insults, resulting in a variety of DNA lesions. Inefficient DNA repair translates into cellular dysfunction and death, but also into the propagation of somatic mutations and malignant transformation. To limit genome instability, cells engage the DNA damage response (DDR) and activate repair mechanisms to reverse or minimize alterations in DNA integrity ${ }^{1}$. The DDR pathway involves the interconnection of complex signaling networks that enforce cell cycle arrest and DNA repair. The failure of this adaptive mechanism is detrimental for the cell, resulting in an irreversible cell cycle arrest (senescence) or the activation of different types of regulated death programs ${ }^{1}$. Accordingly, perturbations in the DDR largely contribute to oncogenesis, tumor progression, and the resistance to irradiation and chemotherapy with genotoxic drugs. The accumulation of synonymous mutations, aneuploidy, as well as the activation of oncogenes, deregulate proteostasis ${ }^{2}$. The endoplasmic reticulum (ER) is the main subcellular compartment involved in protein folding and quality control $^{3}$, representing a central node of the proteostasis network. The unfolded protein response (UPR) is a specialized mechanism to cope with ER stress ${ }^{4,5}$, that also influences most hallmarks of cancer ${ }^{6}$. Nevertheless, the possible involvement of the UPR in the surveillance and maintenance of genome integrity remains elusive.

Inositol requiring enzyme 1 alpha (known as ERN1, referred to as IRE1 $\alpha$ hereafter) controls the most evolutionary conserved UPR signaling branch, regulating ER proteostasis and cell survival through distinct functional outputs ${ }^{4}$. IRE1 $\alpha$ is a serine/threonine protein kinase and endoribonuclease that catalyzes the unconventional splicing of the mRNA encoding X-Box binding protein 1 (Xbp1), generating an active transcription factor that enforces adaptive programs ${ }^{7}$. IRE1 $\alpha$ also degrades a subset of mRNAs and microRNAs through a process known as regulated IREladependent decay of RNA (RIDD), impacting various biological processes, including cell death and inflammation ${ }^{8-11}$. A screen aiming to define the universe of XBP1-target genes under ER stress identified a cluster of DDR-related components ${ }^{12}$, and suboptimal DNA repair may trigger ER stress ${ }^{2}$. Together, these observations suggest a link between DNA damage and ER proteostasis. Here we investigate the possible contribution of IRE1 $\alpha$ to the DDR. Surprisingly, we observed that genotoxic stress engages IRE1a signaling in the absence of ER stress markers. In fibroblasts undergoing DNA damage, IRE1 $\alpha$ activation results in the selective activation of RIDD in the absence of XBP1 mRNA splicing, impacting genome stability, cell survival and cell cycle control. At the molecular level, we identify specific RIDD mRNA substrates as possible effectors of the phenotypes triggered by IRE1 $\alpha$ deficiency. We also validated the significance of IRE1 $\alpha$ signaling to the DDR in vivo using genetic manipulation in mouse and fly models. Our results suggest that IRE1 $\alpha$ has an alternative function in cells undergoing genotoxic stress, where it serves to amplify and sustain an efficient DDR to maintain genome stability and cell survival.

\section{Results}

DNA damage selectively induces IRE1 $\alpha$ signaling toward RIDD. Upon ER stress, IRE1a dimerization leads to its autotransphosphorylation and the formation of large clusters that are needed for optimal signaling ${ }^{13}$. Exposure of mouse embryonic fibroblasts (MEF) to the DNA damaging agent etoposide, a topoisomerase II inhibitor, triggers mild IREla phosphorylation (Fig. 1a) and formation of IRE1a clusters, as revealed using an IRE1a-GFP reporter (Fig. 1b). Similar results were obtained in cells exposed to $\gamma$-irradiation (Supplementary Fig. 1a). Unexpectedly, MEF cells stimulated with etoposide or $\gamma$-irradiation failed to engage Xbp1 mRNA splicing, as determined by two independent PCR-based assays (Fig. 1c, d) or western blot analysis (Supplementary Fig. 1b). Moreover, no signs of ER stress were observed in cells undergoing DNA damage when we assessed canonical markers of UPR activation, including the expression of $\mathrm{CHOP}, \mathrm{ATF} 4, \mathrm{BiP}$, as well as ATF6 processing and the phosphorylation of both PERK and eIF2 $\alpha$ (Supplementary Fig. 1c, d). As positive controls of DNA damage, we monitored the levels of phosphorylation of the histone H2AX $(\gamma-\mathrm{H} 2 \mathrm{AX})$ or the upregulation of the cyclin-dependent kinase inhibitor CDKN1A (also known as p21) (Supplementary Fig. 1b, d). Unexpectedly, classical RIDD mRNAs substrates such as Bloc1s1 and Sparc 8 ,9 decayed upon exposure to DNA damaging agents (Fig. 1e). Importantly, this decrease in Bloc1s1 and Sparc mRNAs did not occur in IRE1 $\alpha$-deficient cells (Fig. 1e), nor upon pharmacological inhibition of the RNase activity of IRE1 $a$ with MKC8866 (Supplementary Fig. 1e, f), confirming the occurrence of RIDD. These results suggest that DNA damage selectively stimulates IRE1 $\alpha$ activity toward RIDD and not Xbp1 mRNA splicing in the absence of global ER stress markers.

IRE1a regulates DDR signaling under genotoxic stress. To evaluate the significance of IRE1a expression to the adaptive capacity of cells undergoing DNA damage, we compared the viability of IRE1 $\alpha$-deficient and control (wild type, WT) cells after exposure to various agents that induce distinct types of DNA lesions, including etoposide, 5-hydroxyurea, 5-fluorouracil, and $\gamma$-irradiation. Remarkably, IRE1a deficiency sensitized cells to all types of genotoxic stress, thus increasing the incidence of cell death (Fig. If and Supplementary Fig. 2a). We confirmed these results by measuring caspase-3 activation, a marker of apoptosis (Fig. 1g). We then stably reconstituted IRE1a null cells with an HA-tagged version of IRE1 $\alpha$ (IRE1 $\alpha-H A)$ that expresses levels similar to endogenous (described in refs. ${ }^{14,15}$ ). Importantly, the hypersensitivity of IRE1a deficient cells to DNA damage was partially reverted by expressing IRE1 $\alpha-\mathrm{HA}$, suggesting that the phenotypes observed in IRE1a-deficient cells under genotoxic stress are a primary phenotype, and are not due to clonal effects or compensatory changes (Supplementary Fig. 2b). In sharp contrast, IRE1a knockout MEFs did not reveal any differential sensitivity to the ER stress inducer tunicamycin, in line with prior results based on pharmacological inhibition of IRE $1 \alpha^{16}$. Also, the pharmacological inhibition of IRE1a RNase activity with MKC8866 increases the susceptibility to cell death after prolonged genotoxic treatments (Fig. 1h, i). These findings highlight the importance of IRE1 $a$ in the adaptation response to DNA damage.

The downstream effects of the DDR are mediated by the activity of check point kinases CHK1 and CHK2, engaging the tumor suppressor protein P53 to induce cell-cycle arrest and the transcription of DNA damage-responsive genes, or to trigger apoptotic cell death ${ }^{17}$. DDR signaling translates into the phosphorylation of histone $\mathrm{H} 2 \mathrm{AX}(\gamma-\mathrm{H} 2 \mathrm{AX})$, and the rate of $\gamma$-H2AX decay after DNA injury is a sign of DNA repair. Thus, we monitored the kinetics of H2AX (de)phosphorylation after exposing cells to a pulse of etoposide. IRE1a null cells exhibited a lower response and faster attenuation of $\gamma-\mathrm{H} 2 \mathrm{AX}$ phosphorylation compared to cells in which IRE1 $\alpha$ was reintroduced (Fig. 2a). Similar results were obtained when cells where exposed to a shorter pulse of a higher concentration of etoposide (Supplementary Fig. 2c). Analysis of nuclear $\gamma-\mathrm{H} 2 \mathrm{AX}$ foci by immunofluorescence and confocal microscopy also indicated reduced $\gamma$-H2AX phosphorylation in IREla deficient cells (Fig. 2b). To corroborate these results, we performed the comet assay to directly visualize the DNA damage observing that IRE1a knockout cells exposed to etoposide exhibited increased 
a

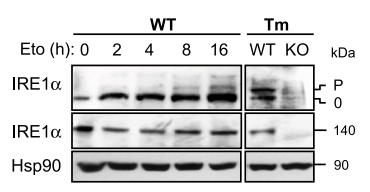

b

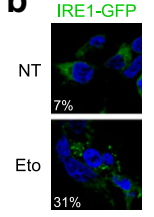

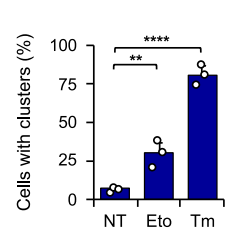

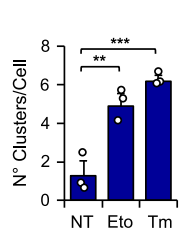

C
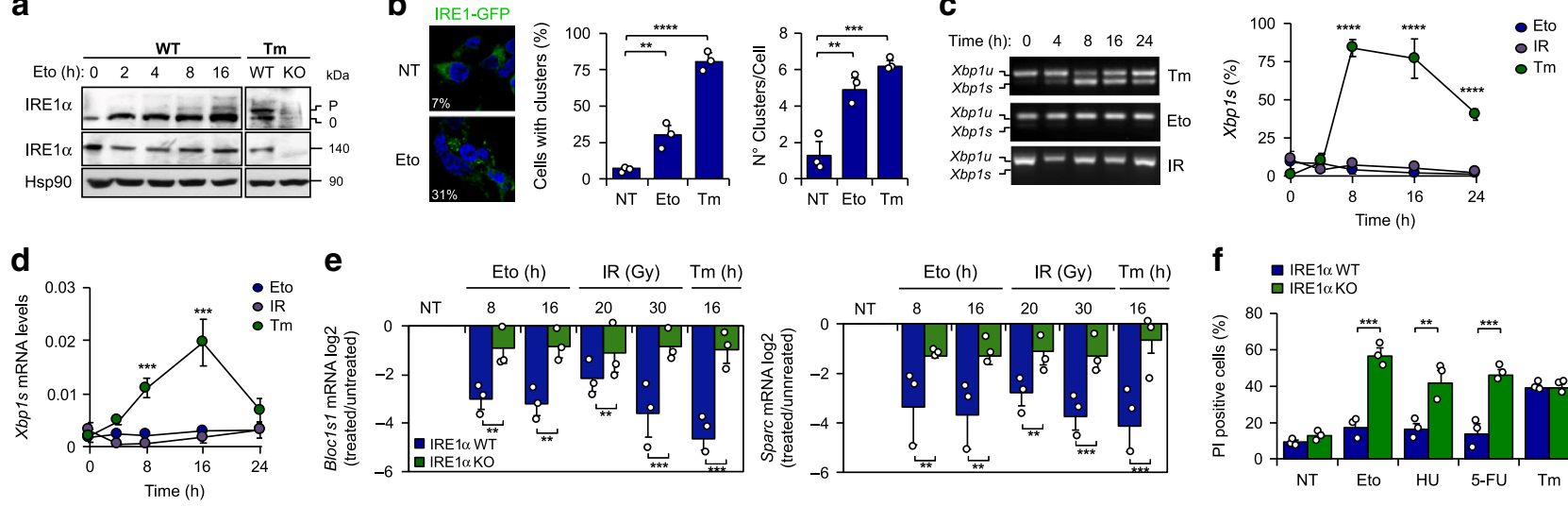

e
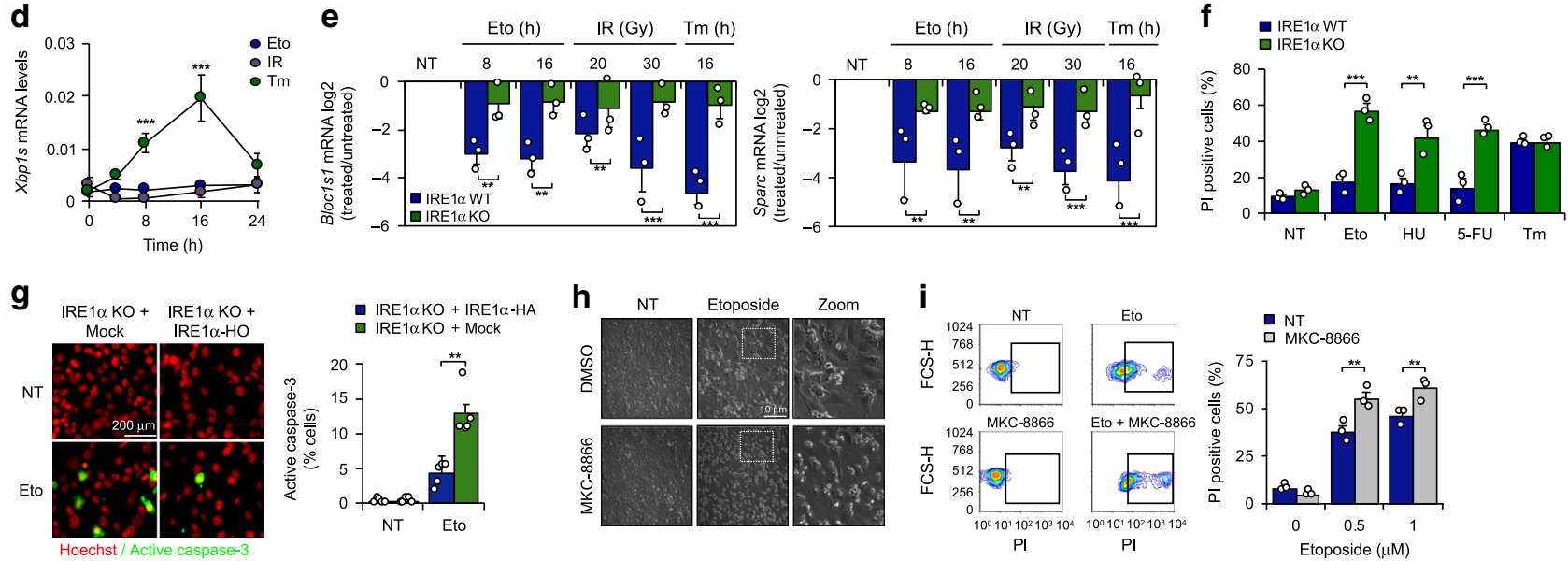

Fig. 1 Selective activation of RIDD under DNA damage. a MEF were treated with $10 \mu \mathrm{M}$ etoposide (Eto) for indicated time points and phosphorylation levels of IRE1 $\alpha$ were detected by Phostag assay ( $p$ : phosphorylated 0: non-phosphorylated bands). IRE1 $\alpha$ levels were analyzed by western blot. Treatment with $500 \mathrm{ng} / \mathrm{mL}$ tunicamicyn $(\mathrm{Tm})$ as positive control $(8 \mathrm{~h})(n=3)$. b TREX-IRE1-3F6H-GFP cells were treated with $25 \mu \mathrm{M} \mathrm{Eto}(8 \mathrm{~h})$ or $1 \mu \mathrm{g} / \mathrm{mL}$ Tm $(4 \mathrm{~h})$. IRE1-GFP foci were quantified by confocal microscopy (>200 cells, $n=3$ ). c MEF were treated with either $100 \mathrm{ng} / \mathrm{mL} \mathrm{Tm,} 10 \mu \mathrm{M}$ Eto or $25 \mathrm{G} \gamma$ of ionizing radiation (IR) at indicated time points. Xbp1 mRNA splicing percentage was calculated by RT-PCR using densitometric analysis (left panel) $(n=3)$. $\mathbf{d}$ Xbp1s mRNA levels were quantified by real-time-PCR in samples described in $\mathbf{c}(n=3)$. e WT and IRE1 $\alpha$ KO cells were treated with $10 \mu \mathrm{M}$ Eto $(8 \mathrm{~h}$ and $16 \mathrm{~h})$, IR (20 or $30 \mathrm{G} \gamma, 16 \mathrm{~h}$ ) and the decay of mRNA levels of Bloc1s1 and Sparc was monitored by real-time-PCR. Treatment with $500 \mathrm{ng} / \mathrm{mL} \mathrm{Tm}$ as positive control $(n=3)$. f WT and IRE $1 \alpha \mathrm{KO}$ cells were treated with $25 \mu \mathrm{M}$ Eto, $1 \mu \mathrm{M}$-fluorouracil (5-FU), $1 \mu \mathrm{M}$ hydroxyurea $(\mathrm{HU})$ or $1 \mu \mathrm{g} / \mathrm{mL} \mathrm{Tm}$ by $24 \mathrm{~h}$ and viability analyzed using propidium iodide (PI) staining and FACS $(n=3)$. g IRE1 $\alpha$ KO (Mock) and IRE1 $\alpha$-HA reconstituted cells were treated with $10 \mu M$ Eto for $12 \mathrm{~h}$ and apoptosis monitored by caspase-3 positive cells (green). Nucleus (Red) was stained to visualize cells number $(n=3)$. $\mathbf{h}$ MEF cells treated $36 \mathrm{~h}$ with $0.5 \mu \mathrm{M}$ Eto in combination with the IRE1 $\alpha$ inhibitor $25 \mu \mathrm{M}$ MKC-8866. Representative images. $\mathbf{i}$ WT cells were treated with 0.5 and $1 \mu \mathrm{M}$ Eto or in combination with $25 \mu \mathrm{M}$ MKC-8866 (36 h). Cell viability analyzed using PI staining and FACS $(n=3)$. All panels data is shown as mean \pm s.e.m.; ${ }^{*} p<0.05$, ${ }^{* \star} p<0.01$, and ${ }^{* \star *} p<0.001$, based on $\mathbf{b}$ two-tailed unpaired $t$-Student's test, (c, d). One-way ANOVA followed Tukey's test (e-g, i), two-way ANOVA followed Bonferroni's test. Data is provided as a Source Data file.

DNA damage (Fig. 2c). We also performed a cytokinesis-block micronucleus cytome (CBMN) assay as an indirect measure of DNA breaks. Cells were incubated with etoposide for $3 \mathrm{~h}$, followed by the administration of cytochalasin-B (CytB) for an additional $24 \mathrm{~h}$. IRE1 $\alpha$ deficiency resulted in a higher percentage of cells with binucleated nuclei, micronuclei or nuclear buds (Fig. 2d). Altogether, these results suggest that IRE1a null cells have reduced engagement of DNA repair programs.

A direct consequence of DNA damage is cell cycle arrest. No significant differences were observed in cell proliferation (Supplementary Fig. 3a) or cell cycle progression between control and IRE1 $\alpha$ null cells in normal conditions. Nevertheless, the fraction of cells arrested in the $S$ and $G_{2} / M$ phases was reduced in IRE1a knockout MEFs exposed to etoposide (Fig. 2e). Similar results were obtained when we reintroduced IRE1 $\alpha$ in knockout cells (Supplementary Fig. 3b). At the molecular level, the ablation of IRE1a expression resulted in a strong attenuation in the phosphorylation of $\mathrm{CHK} 1$ and CHK2 in DNA-damaged cells (Fig. 2f). In contrast, the phosphorylation of the apical kinase ataxia telangiectasia mutated kinase (ATM; an upstream sensor of the DDR) was not altered in IRE1a knockout cells exposed to etoposide (Fig. 2f and Supplementary Fig. 3c). Consistent with these results, IRE1 $a$ knockout and WT MEF cells showed similar phosphorylation of SMC1 $1^{18}$ and $\mathrm{KAP} 1^{19}$, two direct substrates of ATM (Supplementary Fig. 3d), suggesting that the defects triggered by IRE1a deficiency occur downstream of ATM activation regulating $\mathrm{CHK} 1$ and $\mathrm{CHK} 2$ activation. Moreover, IRE1 1 deficient cells showed a sustained kinetic of activation of P53 (Supplementary Fig. 3e). Taken together, these results suggest that IRE1 $\alpha$ deficiency deregulates DDR signaling, thus affecting cell cycle progression, DNA repair and cell survival under genotoxic stress.

Genotoxic stress triggers RIDD to regulate DDR signaling. To obtain mechanistic insights, we attempted to identify RIDD target mRNAs that might connect IRE1a signaling to the DDR. Previously, a global in vitro screening uncovered a cluster of mRNAs containing consensus sequences cleaved by IRE1a that are associated to a stem-loop structurally similar to the Xbp1 mRNA splicing site ${ }^{20}$. Among the 13 top hits, two DDR-related genes were identified as possible RIDD substrates: PPP2CA-scaffolding A subunit (Ppp2r1a) and RuvB like AAA ATPase1 (Ruvbl1) mRNAs $^{21}$ (Fig. 3a). PPP2R1A encodes the scaffold A subunit of protein phosphatase 2 catalytic subunit alpha (PPP2CA, also known as PP2A), which dephosphorylates check point kinases, reversing the G2/M arrest, and directly catalyzing the decay of $\gamma$ $\mathrm{H} 2 \mathrm{AX}$ phosphorylation and foci ${ }^{22}$. RUVBL1 (also known as Pontin), participates in chromatin remodeling and modulates the stability of DDR protein complexes, thus influencing the dephosphorylation of $\gamma-\mathrm{H} 2 \mathrm{AX}^{23}$. 
a

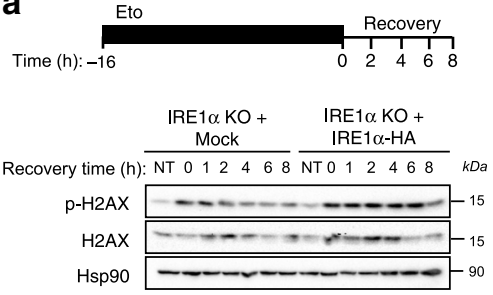

b

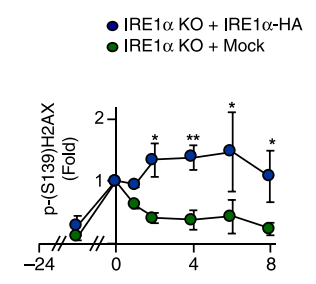

C
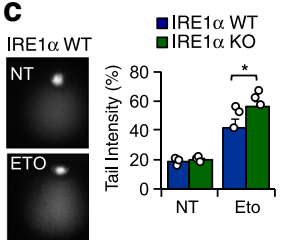

IRE1 $\alpha$ KO

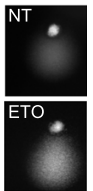

d

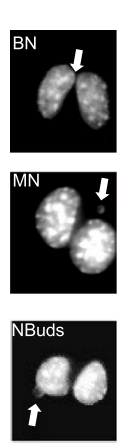

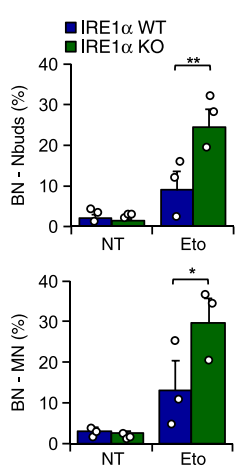

e aSub $G 1$
Gool/G1
as 모
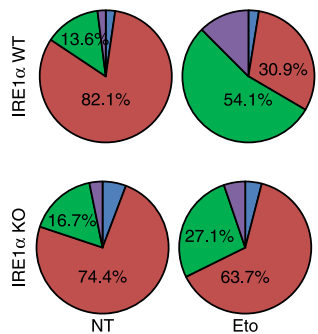
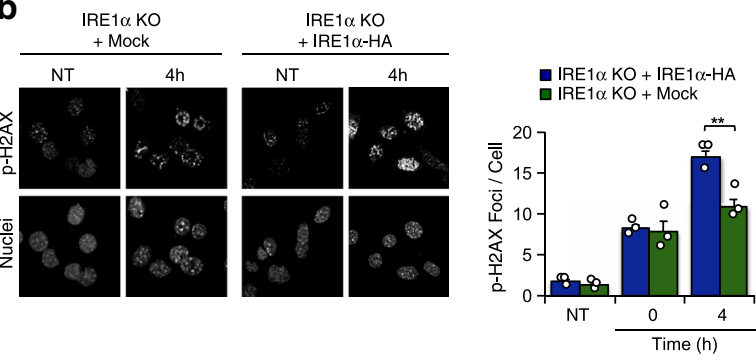

$\mathbf{f}$

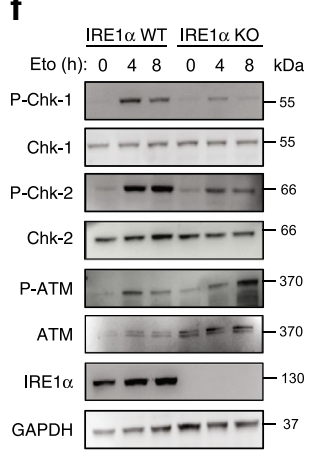

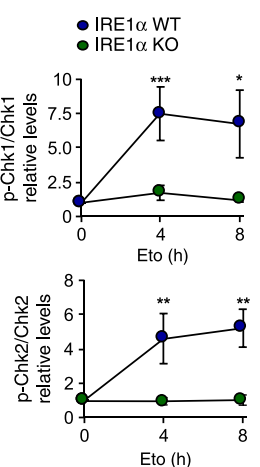

Fig. 2 IRE1 $\alpha$ deficiency impairs the DDR. a IRE1 $\alpha$ KO (Mock) and IRE1 $\alpha$-HA reconstituted cells were pre-incubated with $1 \mu \mathrm{M}$ etoposide (Eto) for $16 \mathrm{~h}$ and washed three times with PBS and fresh cell culture media was added. The decay of phosphorylated $\mathrm{H} 2 \mathrm{AX}(\mathrm{P}-\mathrm{H} 2 \mathrm{AX})$ was monitored over time by western blot (middle panel). Quantification of the levels of P-H2AX in cells stimulated with Eto (bottom panel) $(n=3)$. b IRE1 $\alpha$ KO (Mock) and IRE1 $\alpha-H A$ reconstituted cells were incubated with $10 \mu \mathrm{M}$ Eto for $2 \mathrm{~h}$ and then washed with PBS and fresh culture media was added. The distribution P-H2AX expression (green) was monitored by indirect immunofluorescence using confocal microscopy. Nuclei were staining with DAPI (Blue). Quantification of $\mathrm{P}-\mathrm{H} 2 \mathrm{AX}$ per cell is shown (right panel) $(n=3)$. c WT and IRE1 $\alpha$ KO MEFs cells were treated with $10 \mu \mathrm{M}$ Eto for $3 \mathrm{~h}$ to perform the comet assay. Quantification of tail intensity and tail moment (Tail intensity $\times$ tail area) is shown (right panel) $(n=3)$. d WT and IRE1 $\alpha$ KO MEFs cells were treated with $5 \mu \mathrm{M}$ Eto for $3 \mathrm{~h}$ to determined cytokinesis-block micronucleus cytome assay (CBMC). Binucleated cells (BN) with micronucleus (MN), nuclear buds (Nbuds) or nucleoplasmid bridges (NPB; see arrows) were visualized and quantified using epifluorescence microscopy $(n=3)$. e WT and IRE1 $\alpha$ KO MEFs cells were treated with $10 \mu \mathrm{M}$ Eto for $8 \mathrm{~h}$ and cell cycle was analyzed by propidium iodide (PI) staining. Quantification of the percentage of cells in G0/G1 and S phases is shown. $\mathbf{f W T}$ and IRE1 $\alpha$ KO MEFs cells were treated with $10 \mu \mathrm{M}$ Eto for indicated times. Expression and phosphorylation levels of indicated proteins involved in the DDR were monitored by western blot (left panel). Quantification of the levels of $p-C H K 1$ and $p-C H K 2$ is shown (right panel) ( $n=$ 3). In all panels, data is shown as mean \pm s.e.m.; ${ }^{\star} p<0.05$, ${ }^{\star \star} p<0.01$, and ${ }^{\star \star \star} p<0.001$, based on (a, $\mathbf{c}, \mathbf{d}, \mathbf{f}$ ) two-way ANOVA followed Bonferroni's test, b two-way ANOVA followed Tukey's test. Data is provided as a Source Data file.

Quantification of Ppp2r1a and Ruvbl1 mRNA levels in cells treated with etoposide demonstrated a decay that was dependent on IRE1a expression (Fig. 3b). These effects on mRNA levels translated into reduced protein expression of PP2A and RUVBL1 only in wild-type cells exposed to etoposide and the basal upregulation in IRE1a null cells (Fig. 3c). In a cell-free assay, recombinant IRE1a directly cleaves a fragment of the Ppp2r1a mRNA that contains the RIDD consensus site (spanning nucleotides 1336-1865), but not an adjacent fragment (Fig. 3d). Similarly, IRE1a exhibited RNase activity on Ruvbl1 mRNA, thus cleaving this substrate as efficiently as it's known targets Bloc1s1 mRNA and Xbp1 mRNA (Fig. 3d). This reaction was suppressed by the IRE1 1 inhibitor $4 \mu 8 \mathrm{C}$ (Fig. $3 \mathrm{~d}$ ).

The lack of Xbp1 mRNA splicing under DNA damage conditions might involve inhibitory signals, for example mediated by the downregulation of the tRNA ligase RTCB, the targeting of the Xbp1 mRNA to the ER membrane, or the activity of other regulatory components that are part of IRE1 $\alpha$ clusters and component associated with them ${ }^{24}$. Analysis of RTCB levels revealed no changes in IRE1a knockout cells undergoing DNA damage (Supplementary Fig. 4a). To test if DNA damage inhibits Xbp1 mRNA splicing, we pre-treated cells with tunicamycin for $2 \mathrm{~h}$ and then added etoposide at different time points. Remarkably, etoposide failed to interfere with $X b p 1 \mathrm{mRNA}$ splicing induced by tunicamycin (Fig. 3e). Virtually identical results were obtained when a pulse of etoposide was performed followed by the stimulation of ER stress (Fig. 3g). In contrast, an additive effect was observed on the decay of Bloc1s1 and Sparc mRNAs when ER stress and DNA damaging agents were combined (Fig. 3f, h). These results indicate that DNA damage selectively engages RIDD yet does not cause active suppression of Xbp1 mRNA splicing.

Considering that PP2A and Pontin are upregulated in IRE1 $\alpha$ null cells under genotoxic stress and are involved in the DDR, we attempted to reverse the phenotype of those cells by depleting Ppp2r1a or Ruvbl1 mRNA with suitable short hairpin RNAs (shRNAs) (Supplementary Fig. 4b). Remarkably, knocking down Ppp2r1a or Ruvbl1 in IRE1a null cells augmented the levels of phosphorylated $\gamma-\mathrm{H} 2 \mathrm{AX}$ foci after etoposide treatment during the recovery phase (Fig. 3i). Similar results were obtained when phosphorylated $\gamma$-H2AX was monitored by immunoblot (Supplementary Fig. 4c). Moreover, knocking-down Ppp2r1a and Ruvbl1 expression in IRE1a null cells reestablished normal levels of CHK1 phosphorylation (Fig. $3 \mathrm{j}$ and Supplementary Fig. 4d, e) and increased population of cells in S/G2M after etoposide treatment (Supplementary Fig. 4f). Taken together, these experiments suggest that the regulation of PP2A and Pontin by IRE1a contributes to DDR signaling under genotoxic treatment.

c-Abl triggers IRE1 $a$ activation under DNA damage. Recent studies suggest that IRE1 $\alpha$ activation can occur independently from ER stress, impacting various biological processes including 
a

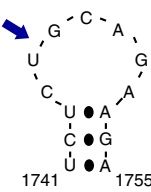

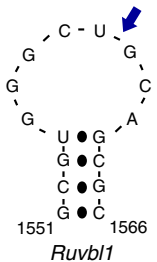

(Oikawa, D., et al. Nucleic Acids Res. 38, 2010)

C

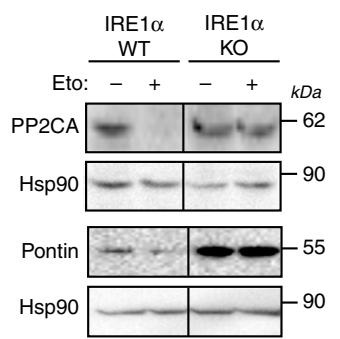

e

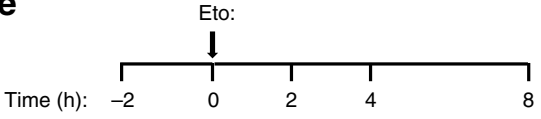

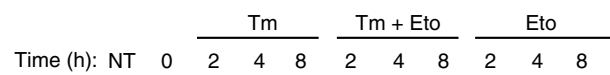

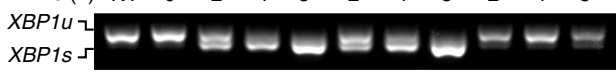

9

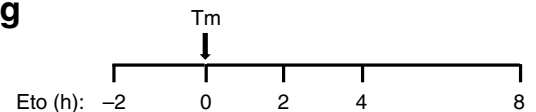

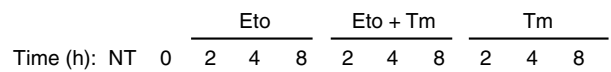
XBP1u
XBP1s

\section{i}
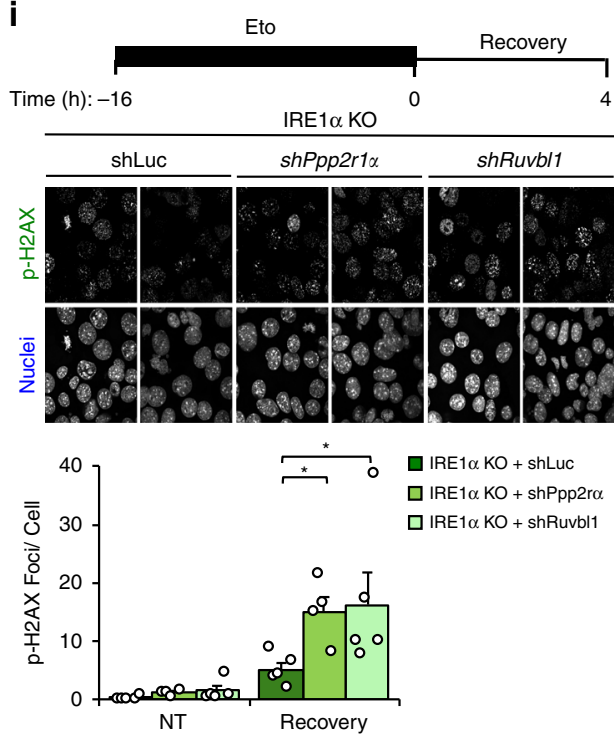

cell migration, synaptic plasticity, angiogenesis and energy metabolism ${ }^{14,24,25}$. However, until now there are no examples for a selective activation of RIDD in the absence of Xbp1 mRNA splicing. The release of the ER chaperone $\mathrm{BiP}$ from the luminal

b

$\mathbf{f}$

j
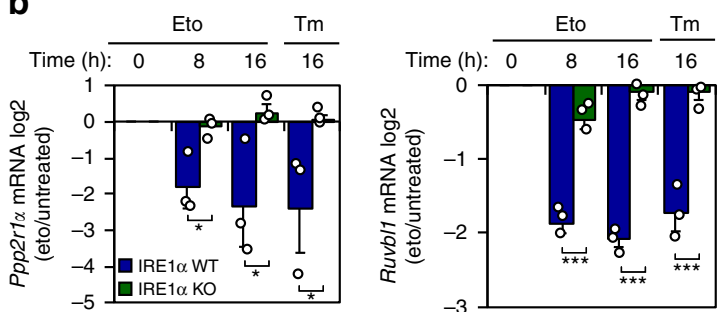

d
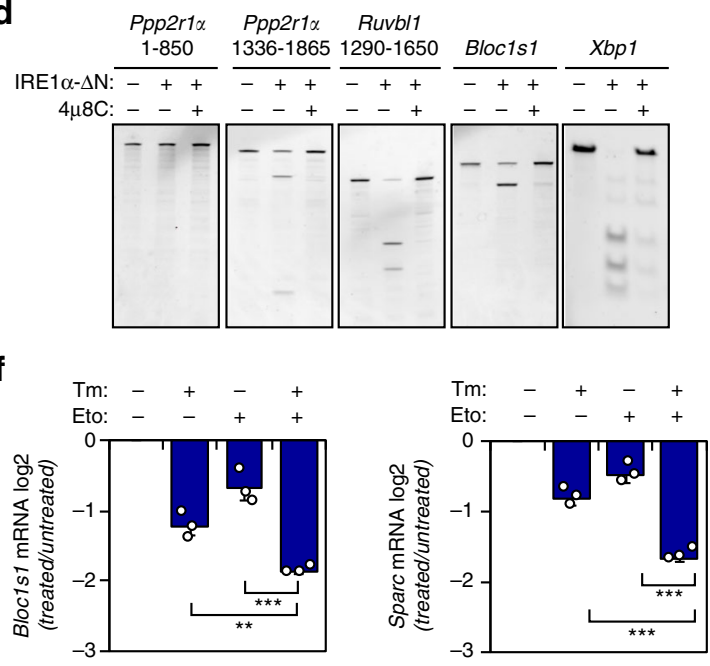

h
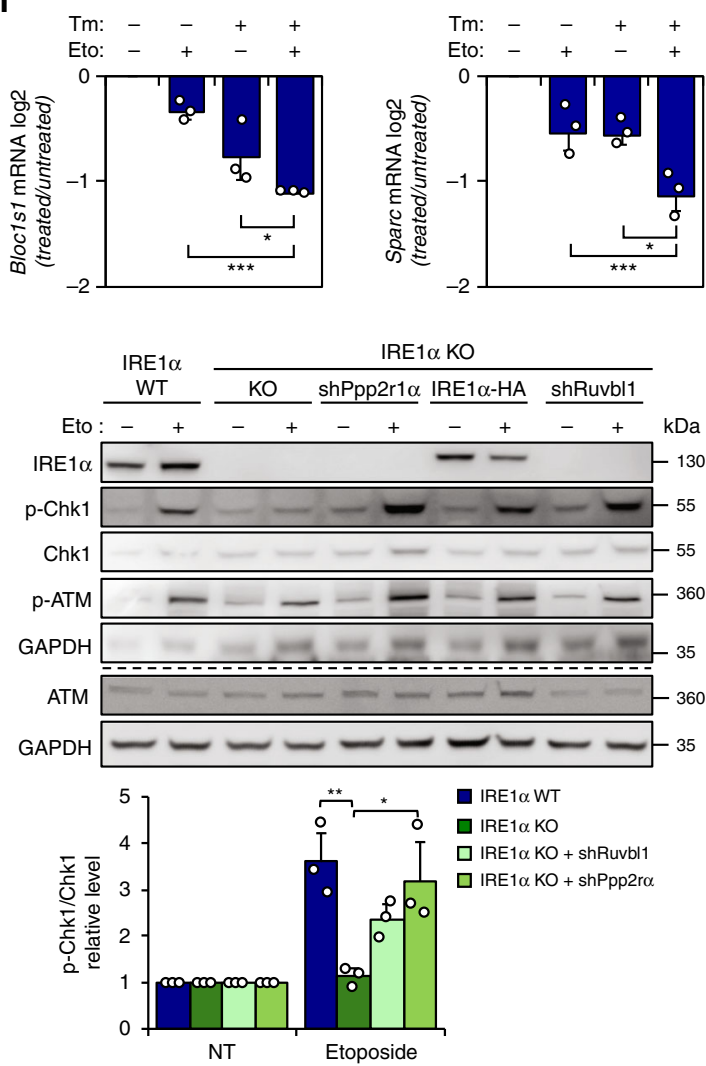

domain of IRE1 a correlates with its activation under ER stress ${ }^{4}$. Co-immunoprecipitation experiments indicated that the $\mathrm{BiP}$ IRE1 $\alpha$ interaction decrease after etoposide treatment, but in a lesser extent than ER stress (Supplementary Fig. 5a). 
Fig. 3 IRE1 $\alpha$ controls the stability of mRNAs involved in the DRR. a Putative IRE1 $\alpha$ cleavage sites on the Ppp2r1a and Ruvb/1 mRNAs (blue arrows). b WT and IRE1 $\alpha$ KO MEF cells were treated with $10 \mu \mathrm{M}$ etoposide (Eto). Ppp2r1a and Ruvbl1 mRNA levels were monitored by real-time-PCR. Treatment with $500 \mathrm{ng} / \mathrm{mL}$ tunicamicyn $(\mathrm{Tm})$ as positive control $(n=3)$. c Cells were treated with $10 \mu \mathrm{M}$ Eto $(16 \mathrm{~h})$ and PP2A and Pontin expression were monitored by western blot $(n=3)$. d In vitro RNA cleavage assay was performed using mRNA fragments of human Ppp2r1a and Ruvbl1, incubated in the presence or absence of recombinant cytosolic portion of IRE1 $\alpha$ (IRE1 $\alpha-\Delta \mathrm{N}$ ) protein (30 min). Experiments were performed in presence or absence of IRE1 $\alpha$ inhibitor $4 \mu 8 \mathrm{C}$. Blos $1 \mathrm{c} 1$ and Xbp1 mRNA were used as positive controls. e Experimental setup (upper panel): MEF cells were pretreated with $100 \mathrm{ng} / \mathrm{mL}$ Tm for $2 \mathrm{~h}$ and then treated with $10 \mu \mathrm{M}$ Eto. Xbp1 mRNA splicing was monitored by RT-PCR (bottom panel). $\mathbf{f}$ RIDD activity was monitored in samples described in e $(n=3)$. $\mathbf{g}$ Experimental setup (upper panel): MEF WT cells were pretreated with $10 \mu \mathrm{M}$ Eto for $2 \mathrm{~h}$ and then treated with $100 \mathrm{ng} / \mathrm{mL}$ Tm. Xbp1 mRNA splicing was monitored by RT-PCR (bottom panel). $\mathbf{h}$ RIDD activity was monitored in samples described in $\mathbf{g}(n=3)$. $\mathbf{i}$ IRE1 $\alpha \mathrm{KO}$ MEF cells were transduced with lentiviruses expressing shRNAs against Ppp2r1a (shPpp2r1a), Ruvbl1 (shRuvbl1) or luciferase (shLuc). Cells were incubated with $1 \mu \mathrm{M} \mathrm{Eto} \mathrm{(16} \mathrm{h),}$ washed three times with PBS and fresh media was added. $\mathrm{P}-\mathrm{H} 2 \mathrm{AX}$ levels were monitored by immunofluorescence after $4 \mathrm{~h}$. $\mathrm{P}-\mathrm{H} 2 \mathrm{AX}$ foci quantification is shown (Bottom panel) (>200 cells, $n=4-5$ ). j WT, IRE1 $\alpha$ KO and reconstituted with IRE1 $\alpha-H A$, expressing shRuvbl1, shPpp2r1a or shLuc cells were treated with $5 \mu \mathrm{M}$ Eto for $8 \mathrm{~h}$ and P-CHK1 and P-ATM monitored by western blot. P-CHK1 quantification is shown (bottom panel) $(n=3)$. All panels data is shown as mean \pm s.e.m.; ${ }^{\star} p<0.05$, ${ }^{\star \star} p<0.01$, and ${ }^{\star \star \star} p<0.001$, based on $\mathbf{b}$ two-way ANOVA followed Bonferroni's test, (f, h-j) One-way ANOVA followed Tukey's test. Data is provided as a Source Data file.

We then explored possible signaling events that may link the DDR with the induction of RIDD. Interestingly, a recent report indicated that the non-receptor c-Abl tyrosine kinase physically interacts with IRE1 $a$ under metabolic stress, allosterically inducing its oligomerization into a conformation that is more likely to catalyze RIDD than Xbp1 mRNA splicing ${ }^{26}$. Of note, c-Abl has been extensively associated to the DDR, regulating cell-cycle arrest and apoptosis ${ }^{27}$. We confirmed the activation of c-Abl under genotoxic stress (Supplementary Fig. 5b). Treatment of cells with the c-Abl inhibitor imatinib reduced the decay of Ruvbll mRNA in cells exposed to tunicamycin or etoposide (Supplementary Fig. $5 c$, d). Furthermore, knocking down the expression of c-Abl using shRNAs (Supplementary Fig. 5e) had no effects on the levels of Xbp1 mRNA splicing (Fig. 4a), but fully prevented the decay of Ruvbl1 and Ppp2rla mRNAs under ER stress or DNA damage (Fig. 4b), phenocopying the consequences of IREla deficiency. Consistent with these results, imatinib treatment attenuated the generation of IRE1a-GFP positive clusters in HEK293 cells undergoing genotoxic stress (Fig. 4c, d). Moreover, we also generated a set of c-Abl null MEF cells using the CRISPR/CAS9 technology (Fig. 4e). The deletion of c-Abl prevented the decay of Ruvbl1, Ppp2r1a (Fig. 4f) and Bloc1s1 mRNAs, without an effect on the levels of Xbp1 mRNA splicing (Supplementary Fig. 5f-g). These observations correlated with the formation of a protein complex between IRE1 $\alpha$ and $\mathrm{c}-\mathrm{Abl}$ as monitored using coimmunoprecipitation in 293T HEK cells overexpressing the proteins (Fig. 4g). We confirmed these results using Proximity Ligation Assay of endogenous c-Abl and IRE1-HA at basal conditions (Fig. 4h) or after exposure to etoposide (Supplementary Fig. 5h, i). Furthermore, using a cell free system, we assessed the effects of recombinant c-Abl on the oligomerization status of purified cytosolic domain of IRE1a. Incubation of purified IRE $1 \alpha$ at $37^{\circ} \mathrm{C}$ induced its spontaneous oligomerization, which was further enhanced when c-Abl was present in the reaction (Fig. 4i). Taken together, these results suggest that the activation of c-Abl in cells undergoing DNA damage contributes to the selective engagement of RIDD, possibly through a direct interaction with IRE1a.

IRE1 $\alpha$ protect flies against genotoxic stress. To test the possible role of IRE1a in the maintenance of genome integrity in vivo, we took advantage of $D$. melanogaster as a model organism. The GAL4/UAS system was employed to knockdown the fly orthologue of IRE1 (dIre1) using RNAi transgenic animals (Supplementary Fig. 6a). Etoposide treatment failed to trigger an increase in the levels of $d X b p 1 s$ mRNA in larval tissue, as monitored by real time PCR (Fig. 5a). However, larvae fed with etoposide or tunicamycin exhibited a similar reduction in the mRNA levels of $d S p a r c$ and $d M y s$, two well-known RIDD targets in flies ${ }^{28}$, in addition to dPontin, fly orthologue of Pontin (Fig. 5b). dIre1 depletion ablated the downregulation of dSparc, $d M y s$ and dPpp2r1a, confirming the occurrence of RIDD (Fig. 5b). Moreover, we then determined the impact of dIrel on the survival of animals under genotoxic conditions and quantified the number of larvae reaching adulthood. Knock-down of dIrel generated a hypersensitivity phenotype, meaning that most etoposide-treated animals died before reaching maturity (Fig. 5 c). Next, we determined the participation of dIre1 in the maintenance of genome integrity. To this end, we performed the somatic mutation and recombination test (SMART). This assay is based on the induction of mutant spots (clones) that arise from loss of heterozygosity in cells of developing animals, which are heterozygous for a recessive wing cell marker mutation (Supplementary Fig. 6b) generating a multiple wing hair (mwh) phenotype (Fig. $5 \mathrm{~d}$, left panel). We expressed a dIre1 RNAi construct in the wing imaginal disc using a Nubbin-Gal4 driver (Nub-Gal4). Exposure to doxorubicin increased the number of mutant spots in the fly wing, and this phenotype was exacerbated upon depletion of dIre1 (Fig. 5d, right panel), suggesting compromised DNA repair. Doxorubicin also caused higher rates of apoptosis-associated caspase-3 activation upon dIre1 knockdown (Fig. 5e). Next, we developed a mosaic analysis to ablate dIre1 expression with a repressible cell marker (MARCM), a strategy that allows the comparison of wild-type and mutant cells in the same tissue by assessing GFP expression (Supplementary Fig. 6c). Using this mosaic technology, we generated mutant clones for dIrel in the eye-antenna imaginal disc and determined the frequency of GFPpositive (dIre1 null cells) and negative cells (WT cells) that persist in the tissue after etoposide treatment. While dIrel expressing cells maintained their viability after exposure to etoposide (Fig. $5 \mathrm{f}$, left panels), dIre1 null cells proved highly susceptible to this genotoxic agent (Fig. 5f, right panels). Taken together, these results indicate that the fly orthologue of IRE1a protects against genotoxic stress in vivo.

IRE1 $\alpha$ deficiency impairs the DDR in mice. We then moved forward and investigated the significance of IREla expression to the DDR in vivo and deleted the RNase domain of IRE1a in the liver and bone marrow using a conditional knockout (cKO) system controlled by the Mx-Cre system ${ }^{29}$. Poly[I:C] was injected to induce Cre expression, and three weeks later animals were treated with a single dose of either etoposide or tunicamycin, followed by the analysis of liver tissue. A well-established mammalian model of ER stress consists in the intraperitoneal injection 
a

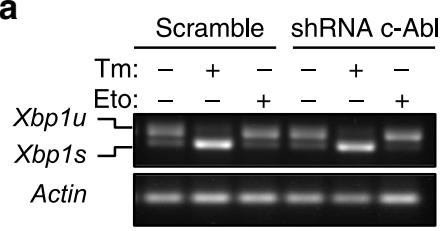

b

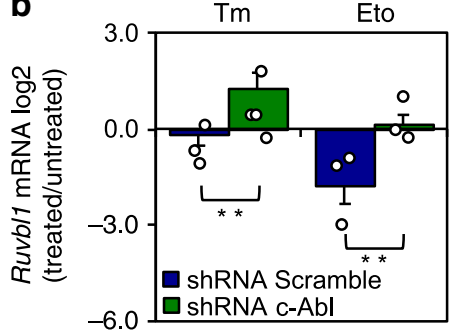

d

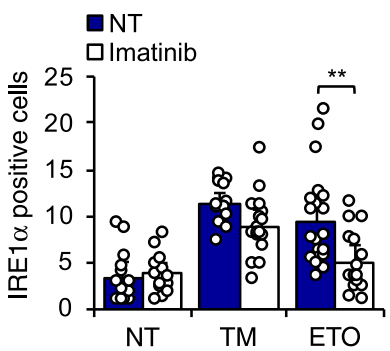

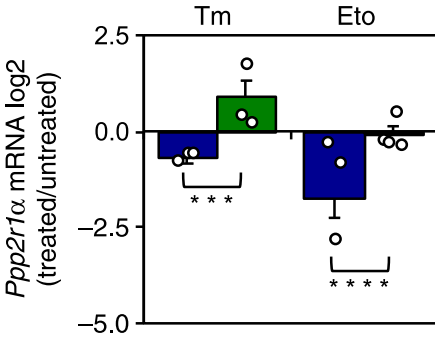

e

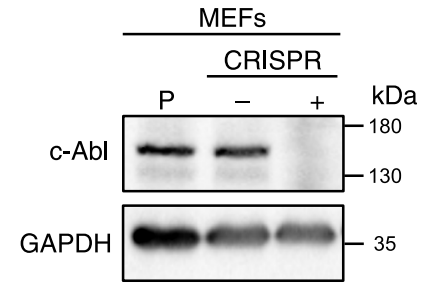

f
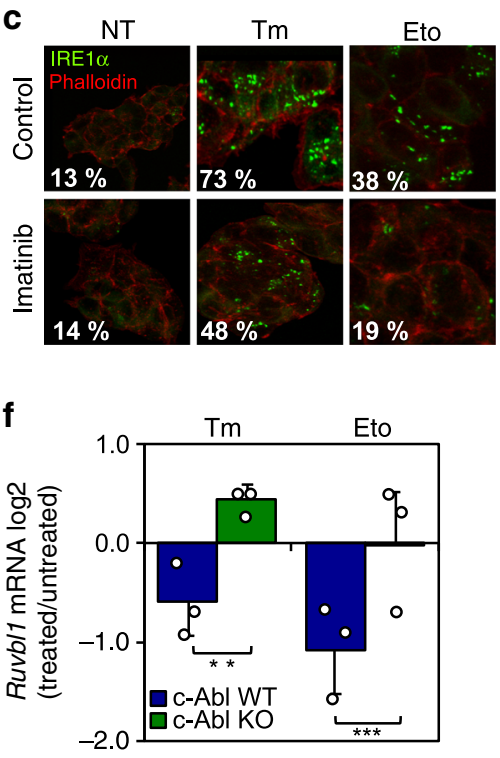

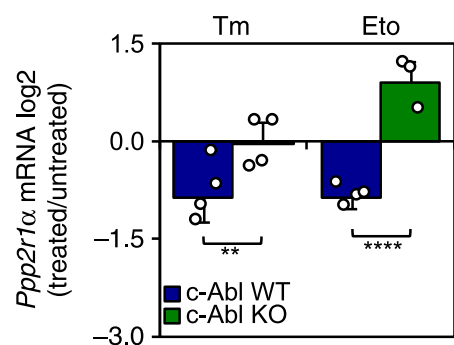

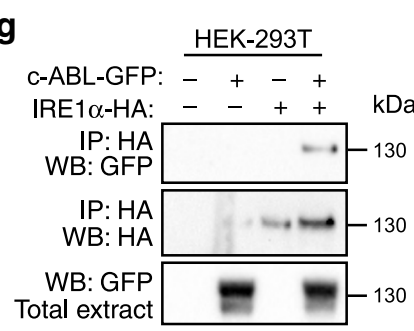

i

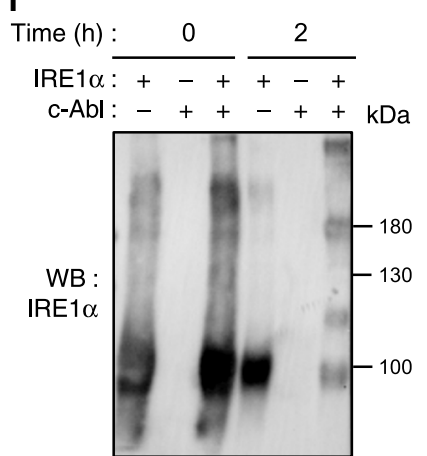

Fig. 4 c-Abl contributes to the RIDD activation under DNA damage. a c-Abl was knocked down through the stable delivery of an shRNA. Then cells were treated with $10 \mu \mathrm{M}$ Etoposide (Eto) or $500 \mathrm{ng} / \mathrm{mL}$ tunicamicyn $(\mathrm{Tm})$ for $8 \mathrm{~h}$ and Xbp1 mRNA splicing was monitored by RT-PCR ( $n=3$ ). b MEF ShRNA Scramble and ShRNA c-Abl cells were treated with $10 \mu \mathrm{M}$ Eto or $500 \mathrm{ng} / \mathrm{mL} \mathrm{Tm}$ for $8 \mathrm{~h}$, and the decay of Ppp2r1a and Ruvb/1 was measured by real-timePCR $(n=3)$. c Trex-IRE1-GFP cells were pre-treated with $10 \mu \mathrm{M}$ imatinib by $1 \mathrm{~h}$, and then treated with $10 \mu \mathrm{M}$ Eto, or $500 \mathrm{ng} / \mathrm{mL}$ Tm for $8 \mathrm{~h}$ and IRE1-GFP foci visualized by confocal microscopy. d Quantification of the percentage of cells positive IRE1-GFP clusters is shown ( $>200$ cells, $n=3)$. e c-Abl expression in CRISPR control and c-Abl KO cells was monitored by western blot $(n=3)$. $\mathbf{f}$ CRISPR control and c-Abl KO cells were treated with $10 \mu M$ Eto or $500 \mathrm{ng} / \mathrm{mL} \mathrm{Tm}$ for $8 \mathrm{~h}$, and the decay of Ruvbl1 and Ppp2r1a was measured by Real-Time-PCR $(n=3)$. $\mathbf{g}$ HEK-293T cells reconstituted with IRE1 $\alpha$-HA and c-Abl-GFP were exposed to $10 \mu \mathrm{M}$ Eto for $8 \mathrm{~h}$. Immunoprecipitation (IP) was performed using the HA epitope (IRE1 $\alpha$ ) and GFP (c-AbI) to assess the possible interaction with c-Abl. $\mathbf{h}$ IRE1 $\alpha \mathrm{KO}$ (Mock) and reconstituted cells with an IRE1 $\alpha$-HA were treated $8 \mathrm{~h}$ with $10 \mu \mathrm{M}$ Eto and stained with a proximity ligation assay (PLA) using an anti-HA or anti-c-Abl antibodies and analyzed by confocal microscopy. Right panel: Number of dots per cell analyzed and percentage of PLA positive cells were quantified $(n=6)$. i Recombinant IRE1 $\alpha$ and c-Abl proteins were incubated at indicated time points and assess its possible interaction by western blot. All data represents the mean \pm s.e.m. of three independent experiments, except for co-IP that were performed twice. ${ }^{\star} p<0.05,{ }^{* \star} p<0.01$, and ${ }^{\star \star *} p<0.001$, based on (b, f) two-way ANOVA followed Bonferroni's test, $(\mathbf{d}, \mathbf{h})$ One-way ANOVA followed Tukey's test. Data is provided as a Source Data file.

of tunicamycin, which elicits a rapid stress response in the liver. Although evident signs of DNA damage were observed in both control and IRE $1 \alpha^{\mathrm{cKO}}$ animals (indicated by a rise in $p 21 \mathrm{mRNA}$ ) (Fig. 6a upper panel and Supplementary Fig. 7a), no Xbp1 mRNA splicing was detected in the etoposide treated group (Fig. 6a, bottom panel). In sharp contrast, a clear down-regulation of Ppp2r1a and Bloc1s1 mRNA levels occurred in the livers (Fig. 6b) and bone marrows (Supplementary Fig. 7b) from control (but not 
a

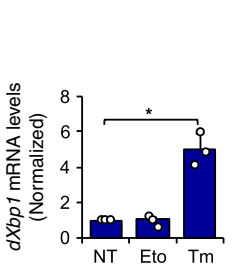

d

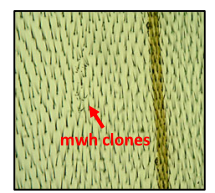

b

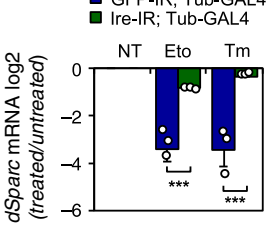

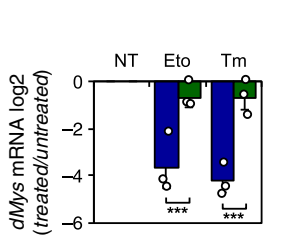

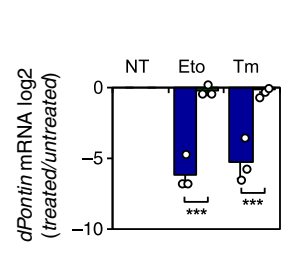

C GFP-IR; Tub-GAL4

C GFP-IR; Tub-GAL4
a Ire-IR; Tub-GAL4

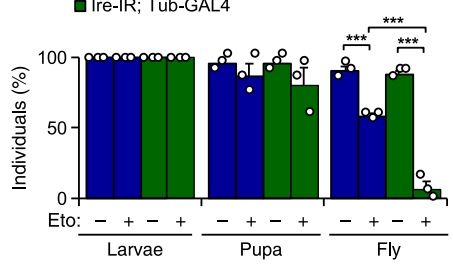

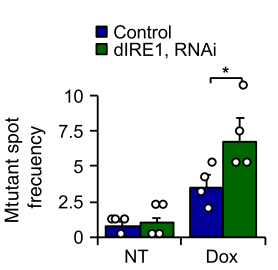

e

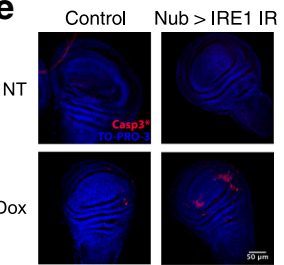

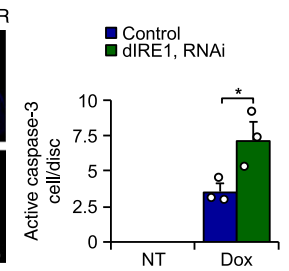
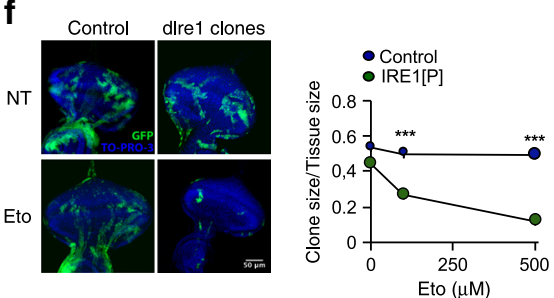

Fig. 5 IRE1 $\alpha$ expression confers protection against genotoxic stress in fly models. a $D$. melanogaster larvae were fed with $100 \mu M$ etoposide (Eto) or $50 \mu \mathrm{g} / \mathrm{ml}$ tunicamycin $(\mathrm{Tm})$ for $4 \mathrm{~h}$ and then $d X b p 7 s$ mRNA evaluated by real-time PCR and normalized to the expression levels of $d R p / 32 \mathrm{gene}(n=3)$. b dlre1 mRNA was knocked down by expressing a specific RNAi constructs under the control of tubulin-Gal4 driver. D. melanogaster larvae were fed with $100 \mu \mathrm{M}$ Eto or $50 \mu \mathrm{g} / \mathrm{ml} \mathrm{Tm}$ for $4 \mathrm{~h}$ and the decay of RIDD targets dSparc, dPontin, and dMys mRNA was evaluated by RT-qPCR and normalized to the expression levels of $d R p / 32$ mRNA $(n=3)$. c Control and dlre1 knockdown larvae were fed with $500 \mu M$ Eto and allowed to reach adulthood for survival analysis. The number of hatched flies was quantified ( $n=20$ per group) $(n=3)$. d A dlre1-RNAi expressing fly line was generated to specifically target dlre1 in the imaginal disc of $D$. melanogaster. The wing SMART assays test was used to monitor genomic alterations after targeting dlre1 in flies. Larvae in first instar were grown in food supplemented with the DNA damaging agent $0.125 \mathrm{mg} / \mathrm{ml}$ doxorubicin (Dox) or 0.5\% DMSO as control. Adult flies from control and dlre1 RNAi larvae were fixed and the left wing analyzed for the number of mwh clones (right panel) ( $n=3$ ). e Using the same experimental setting described in $\mathbf{d}$, imaginal discs were collected, fixed and caspase-3 positive cells detected by immunofluorescence. Nucleus was stained with TO-PRO3 to visualize total number of cells. Quantification of active caspase-3 cells per imaginal disc is presented (right panel) ( $n=3$ ). $\mathbf{f}$ Mutant knockout dlre1 cells (dlre1 clone) in the eye-antenna imaginal disc were marked with GFP (see methods). Quantification of the ratio clone size/disc size is presented (right panel) ( $n=10$ clones). In all panels, data is shown as mean \pm s.e.m.; ${ }^{\star} p<0.05$, ${ }^{\star \star} p<0.01$, and ${ }^{* \star *} p<0.001$, based on a one-way ANOVA followed Tukey's test, b-f two-way ANOVA followed Bonferroni's test. Data is provided as a Source Data file.

IRE1 $\alpha$-deficient) animals injected with etoposide. Again, no Xbp1 mRNA splicing was detected in the etoposide treated group, whereas exposure of animals to tunicamycin triggered a very mild response in bone marrow tissue (Supplementary Fig. 7c). In addition, IRE1 $\alpha$ deficiency in the liver altered the DDR, reflected in reduced phosphorylation of CHK1 in animals injected with etoposide (Fig. 6c). Importantly, ablation of IRE1 $\alpha$ resulted in enhanced susceptibility of liver cells to apoptosis measured as enhanced caspase-3 activation (Fig. 6d).

Finally, to assess the significance of IRE1 $\alpha$ to the DDR on an unbiased manner, we performed a gene expression profile analysis of liver tissue derived from mice exposed to etoposide or tunicamycin. Pathway enrichment analysis indicated that IRE1a deficiency attenuated the establishment of a global DDR, delayed the expression of cell cycle arrest genes and activated proapoptotic pathways (Fig. 6e and Supplementary Fig. 8a). As expected, under ER stress induced by tunicamycin, IRE1a deficiency in the liver significantly impacted the expression of genes involved in proteostasis control in the secretory pathway (trafficking, folding and quality control) (Supplementary Fig. $8 b, c)$. Taken together, these findings demonstrate that IRE1a signaling contributes to maintaining the stability of the genome when cells face DNA damage.

\section{Discussion}

The current study supports a conserved function for IRE1a as a signaling module of the DDR that differs from its canonical role as an UPR mediator. We propose that IRE1a is part of a key decision-making node in a complex interplay between cell survival and DNA repair upon genotoxic stress. In this context, IRE1 a regulates the levels of PP2A and RUVBL1 through the selective engagement of RIDD, controlling the kinetics and amplitude of $\gamma$-H2AX phosphorylation. The contribution of IRE1 $\alpha$ to genome stability is conserved in evolution from insects to mammals and impacts whole animal survival as demonstrated using flies. Our results suggest a regulatory mechanism in which the RNase domain of IRE1 $\alpha$ is selectively regulated to specifically engage RIDD, presumably upon interaction with c-Abl (Fig. 4g, h). This view is consistent with recent studies that connected using unbiased approaches the pathways involved in maintenance of genome integrity and proteostasis, showing that dysregulation of the DDR resulted in protein aggregation and autophagy induction $^{30,31}$. Moreover, previous work demonstrated that the function and structure of the ER is drastically affected by DNA damaging agents used in chemotherapy ${ }^{32,33}$. Other recent reports suggested that chronic ER stress suppresses DNA repair and sensitizes cancer cells to ionizing radiation and chemotherapy ${ }^{34-37}$, in addition to enhancing oxidative damage to the $\mathrm{DNA}^{38}$. Interestingly, a recent study also reported that $\mathrm{XBP} 1 \mathrm{u}$, the protein encoded by the unspliced version of $X b p 1$ mRNA, regulates the stability of TP53, suggesting alternative connections between the UPR and the DDR under resting conditions ${ }^{39}$. Our results suggest that IRE1a specifically affects signaling events regulating the DDR, and not the DNA damage sensing process. IRE1 $\alpha$ operates as an amplification loop, impacting the sustained activation of $\mathrm{CHK} 1 / 2$ and the phosphorylation of $\gamma-\mathrm{H} 2 \mathrm{X}$ through the control of the RIDD targets Ppp2rla and Ruvbl1, leading to cell cycle arrest and improved DNA repair and as a consequence maintenance of cell survival (see working model in Fig. 6f).

Although RIDD is proposed to be necessary for the maintenance of ER homeostasis 8,10 and to contribute to the pathogenesis of diabetes ${ }^{5}$, cancer ${ }^{40,41}$, and inflammatory conditions ${ }^{42-44}$, most of the available evidence is difficult to interpret due to the concomitant existence of Xbp1 mRNA splicing. Our study supports a fundamental biological function for RIDD in the maintenance of 
a

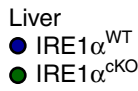

Liver

- IRE $1 \alpha^{\mathrm{WT}}$

IRE1 $\alpha^{\mathrm{cKO}}$

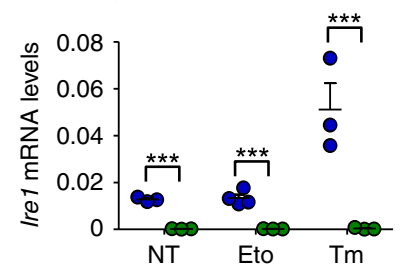

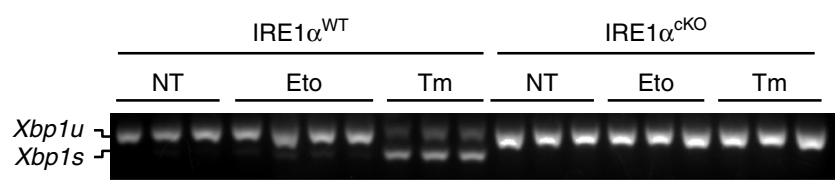

C

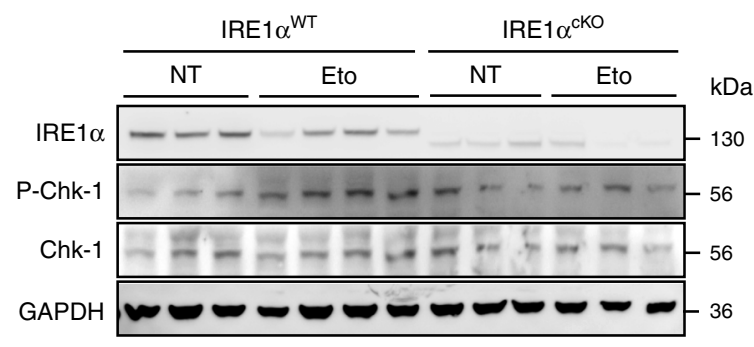

e

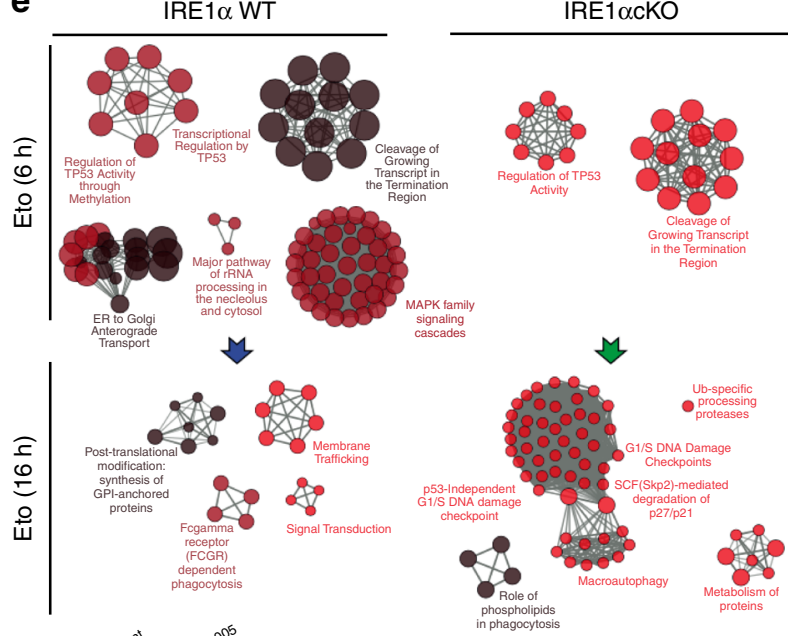

b Liver
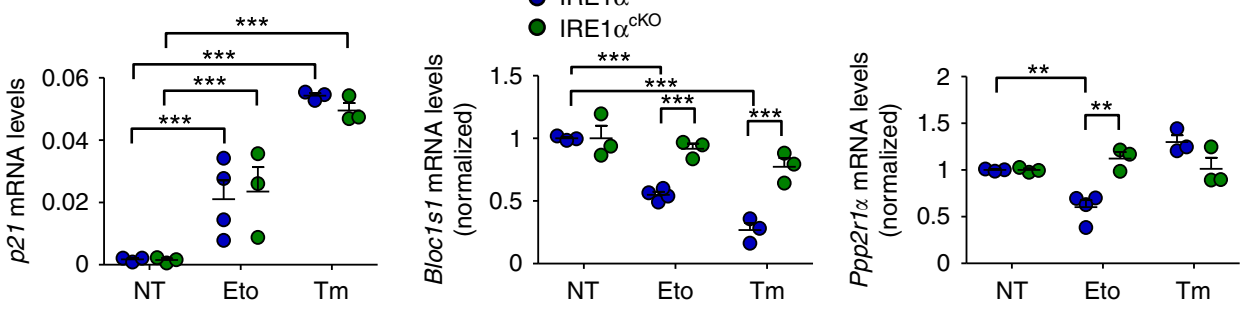

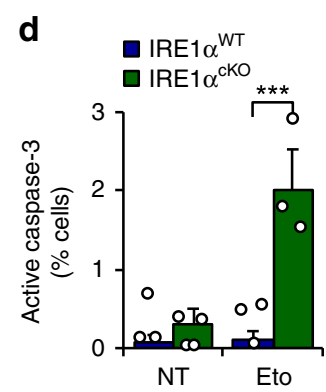

f

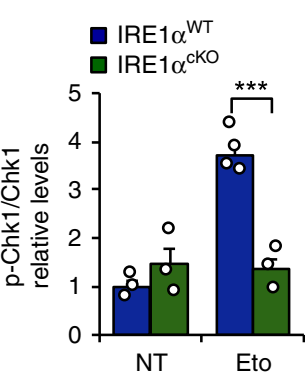

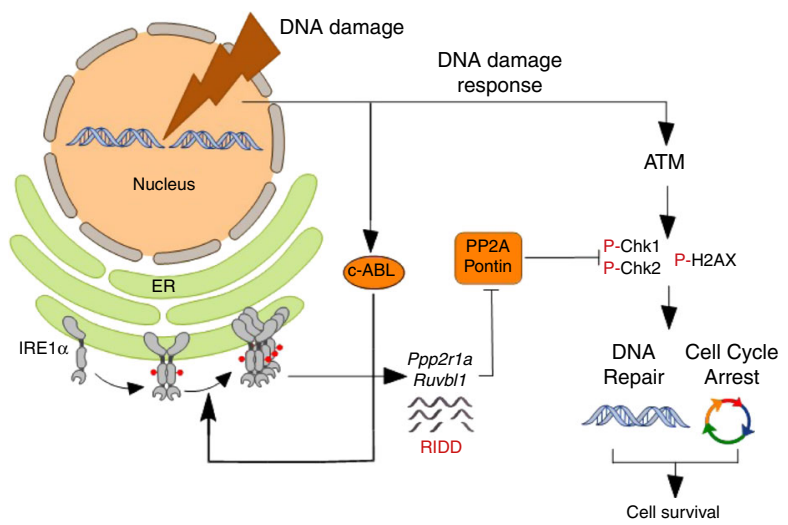

Fig. 6 IRE1 $\alpha$ deletion in liver alters the DDR under genotoxic stress. a IRE1 $\alpha$ was conditionally deleted the liver using the MxCre and LoxP system $\left(\right.$ IRE $1 \alpha^{\mathrm{CKO}}$ ). Mice were intraperitoneally injected with $50 \mathrm{mg} / \mathrm{Kg}$ etoposide (Eto) or $1 \mathrm{mg} / \mathrm{Kg}$ tunicamycin (Tm) and sacrificed $6 \mathrm{~h}$ and $16 \mathrm{~h}$ later. Total mRNA levels of the deleted IRE1, and $p 21$ were measured $6 \mathrm{~h}$ later in the liver by real-time-PCR ( $n=3-4$ mice per group). Xbp1 mRNA splicing (bottom panel) was monitored in the same samples by RT-PCR. $\mathbf{b}$ Liver extracts of animals described in a, Ppp2r1a and Bloc1s1 mRNA expression levels were measured $6 \mathrm{~h}$ later of Eto treatment by real-time-PCR $(n=3)$. c Protein liver extracts were obtained from mice treated described in $\mathbf{a}$ and the expression levels of indicated proteins were monitored $6 \mathrm{~h}$ later of Eto treatment by western blot. Quantification of the levels of $p$-CHK1 is shown (Right panel). $\mathbf{d}$ Mice from a were intraperitoneally injected with $50 \mathrm{mg} / \mathrm{Kg}$ Eto and sacrificed $48 \mathrm{~h}$ later. Then, livers active-caspase 3 detected by immunohistochemistry ( $n=$ 2-3). e Gene expression profile analysis was performed in mRNA from liver extracts of animals described in a. Most significant pathways altered by Eto administration in WT and IRE1 $\alpha$ null livers are shown. Three independent biological samples were used. In all panels, data is shown as mean \pm s.e.m.; ${ }^{*} p<$ $0.05,{ }^{\star \star} p<0.01$, and ${ }^{\star \star \star} p<0.001$, based on a-d two-way ANOVA followed Bonferroni's test. Data is provided as a Source Data file. $\mathbf{f}$ Working model: genotoxic stress activates IRE1 $\alpha$ in the absence of ER stress markers, selectively engaging RIDD. IRE1 $\alpha$ degrades mRNAs involved in the DNA damage response encoding for Ppp2r1a and Ruvbl1, regulating the (de)phosphorylation of the histone H2AX and CHK-1/2. The non-canonical activation of IRE1 $\alpha$ involves the participation of the c-Abl kinase that is activated by DNA damage response kinases as ATM. The expression and function of IRE1 $\alpha$ is essential to promote survival under DNA damage conditions by controlling cell cycle arrest and DNA repair programs. 
genome integrity, representing a unique example for a selective and specific activation of RIDD with clear physiological implications. IRE1a is frequently affected by loss-of-function mutations in cancer $^{2,45}$, contrasting with the notion that cancer cells require IRE1a to survive in hypoxic conditions ${ }^{3,6}$. Our present results support the idea that the genetic alterations of IRE1a observed in cancer may synergize with oncogenes to promote genomic instability due to inefficient DNA repair. Altogether, we uncovered a previously unanticipated function of a major UPR signal transducer as an integral component of the DDR, revealing an intimate connection between the pathways that assure the integrity of the proteome and the genome.

\section{Methods}

Reagents. Etoposide, doxorubicin, 5-fluorouracil, hidroxyurea, imatinib and $4 \mu 8 \mathrm{C}$ were purchased from Sigma Aldrich. Tunicamycin was obtained from Calbiochem EMB Bioscience Inc. IRE1 inhibitor MKC-8866 was provided by Dr. John Patterson (Fosun Orinove). Cell culture media, fetal calf serum, and antibiotics were obtained from Life Technologies and Sigma Aldrich. Fluorescent probes and secondary antibodies coupled to fluorescent markers were purchased from Molecular Probes, Invitrogen. All other reagents were obtained from Sigma or the highest grade available.

Cell culture and DNA constructs. All MEF and HEK cells used here were maintained in Dulbecco's modified Eagles medium supplemented with 5\% fetal bovine serum, non-essential amino acids and grown at $37^{\circ} \mathrm{C}$ and $5 \% \mathrm{CO}_{2}$. IRE1a deficient cells were previously described ${ }^{25}$. The production of amphotropic retroviruses using the HEK293GPG packing cell line was performed as described in ref. ${ }^{46}$. Retroviral plasmids were transfected using Efectene (Qiagen, Valencia, CA, USA) according to the manufacturer's protocols. IRE1 $\alpha-H A$ expressing retroviruses were previously described in the pMSCV-Hygro vector ${ }^{46}$, where IRE1 $\alpha$ contains two tandem HA sequences at the C-terminal domain and a precision enzyme site before the HA tag.

RNA isolation, RT-PCR and real time PCR. Total RNA was prepared from cells and tissues using Trizol (Invitrogen, Carlsbad, CA, USA), and cDNA was synthesized with SuperScript III (Invitrogen) using random primers $\mathrm{p}(\mathrm{dN}) 6$ (Roche). Quantitative real-time PCR reactions were performed using SYBRgreen fluorescent reagent and/or EvaGreen ${ }^{\mathrm{TM}}$ using a Stratagene Mx3000P system (Agilent Technologies, Santa Clara, CA 95051, United States). The relative amounts of mRNAs were calculated from the values of comparative threshold cycle by using Actin as a control and Rpl19 or Rpl32 for RIDD substrates in mouse or D. melanogaster samples, respectively. All methods for Xbp1 mRNA splicing assay were previously described in ref. ${ }^{47}$ using primers described in Supplementary Table 1.

Immunoprecipitations. HEK-293T cells reconstituted with IRE1 $\alpha-\mathrm{HA}$ and c-AblGFP and IRE1a deficient MEF cells stably transduced with retroviral expression vectors for IRE1 $\alpha$-HA or empty vector were incubated in presence or absence of tunicamycin $(500 \mathrm{ng} / \mathrm{mL}$ for $4 \mathrm{~h})$ or etoposide $(10 \mu \mathrm{M}$ for $16 \mathrm{~h})$. Cell lysates were prepared for immunoprecipitations in lysis buffer $(0.5 \% \mathrm{NP}-40,50 \mathrm{mM} \mathrm{NaCl}$, $50 \mathrm{mM}$ Tris $\mathrm{pH}$ 7.6, $50 \mathrm{mM} \mathrm{NaF}, 1 \mathrm{mM} \mathrm{Na}_{3} \mathrm{VO}_{4}$ and protease inhibitors). Immunoprecipitations (IP) were performed as described ${ }^{48}$. In brief, to IP HAtagged IRE1 $\alpha$, protein extracts were incubated with anti-HA antibody-agarose complexes (Roche), for $4 \mathrm{~h}$ at $4^{\circ} \mathrm{C}$, and then washed three times with $1 \mathrm{~mL}$ of lysis buffer and then one time in lysis buffer with $350 \mathrm{mM} \mathrm{NaCl}$. Beads were dried and resuspended in Sample Buffer 2x. Samples were heated for $5 \mathrm{~min}$ at $95^{\circ} \mathrm{C}$ and resolved by SDS-PAGE $8 \%$ followed by western blot analysis.

Western blot analysis. Cells were collected and homogenized in RIPA buffer (20 mM Tris $\mathrm{pH} 8.0,150 \mathrm{mM} \mathrm{NaCl}, 0.1 \%$ SDS, $0.5 \%$ Triton X-100) containing a protease inhibitor cocktail (Roche, Basel, Switzerland) in presence of $50 \mathrm{mM} \mathrm{NaF}$ and $1 \mathrm{mM} \mathrm{Na}_{3} \mathrm{VO}_{4}$. Protein concentration was determined in all experiments by micro-BCA assay (Pierce, Rockford, IL), and 20-40 $\mu \mathrm{g}$ of total protein was loaded onto $8-12 \%$ SDS-PAGE minigels (Bio-Rad Laboratories, Hercules, CA) prior transfer onto PVDF membranes. To evaluate IRE1 $\alpha$ phosphorylation, SDS-PAGE minigel were made in presence of the $5 \mu \mathrm{M}$ of Phostag reagent and $10 \mu \mathrm{M} \mathrm{MnCl}_{2}$. Membranes were blocked using PBS, 0.1\% Tween-20 (PBST) containing 5\% milk for $60 \mathrm{~min}$ at room temperature then probed overnight with primary antibodies. The following antibodies diluted in blocking solution were used in this study: antiBiP 1:1000 (Abcam, Cat. ab21685); Anti-phosphorylated S139-H2AX 1:5000 (Millipore, Cat. 05-636), anti-DDIT3 (CHOP) 1:1000 (Santa Cruz, Cat. sc-575), anti-XBP1s 1:1000 (Santa Cruz, Cat. 7160), anti-ATF4 1:2000 (Santa Cruz, Cat. sc200), anti-Hsp90 1:5000 (Santa Cruz, Cat. sc-13119), anti-IRE1 a (14C10) (Santa Cruz, Cat. 3294), anti-Chk1 1:1000 (Santa Cruz, Cat. sc-8408), anti-Chk2 1:1000 (Santa Cruz, Cat. sc-17747), anti-phosphorylated-Chk2, Thr68 1:1000 (Santa Cruz, Cat. sc-16297-R), anti-ATM 1:1000 (Santa Cruz, Cat. sc-7129), anti-HA 1:1000
(Roche, Cat. 11666606001), anti-PP2A A 1:1000 (Cell Signaling technology, Cat. 2041S), anti-RuvbL1 1:1000 (Cell Signaling technology, Cat. 12300), anti-eIF2a 1:000 (Cell Signaling technology, Cat. 9722), anti-phosphorylated-eIF2a 1:1000 (Cell Signaling technology, Cat. 9721), anti-PERK 1:1000 (Cell Signaling technology, Cat. 3192), anti-IRE1a 1:1000 (Cell Signaling technology, Cat. 3294), antiphosphorylated-Chk1, Ser348 1:1000 (Cell Signaling, Cat. 2341), anti-HA 1:1000 (Cell Signalling, Cat. 3724), anti-GAPDH 1:1000 (Cell Signaling, Cat. 21185), antiAbl 1:1000 (Sigma, Cat. A5844), anti-phosphorylated-c-Abl, pTyr412, 1:1000 (Sigma, Cat. C52490), anti-SMC1 1:1000 (Abcam, ab21583), anti-phosphorylatedSMC1,Ser957, 1:1000 (Abcam, ab137871), anti-KAP1, 1:1000 (Abcam, ab190178), anti-phosphorylated-KAP1, Ser824, 1:1000 (Abcam, ab70369), antiphosphorylated-ATM Ser 198 1:1000 (MERK, Cat. 05-740), anti-p21 (Santa Cruz, Cat. sc-6246), anti-phospho-p53 (Cell Signalling, Cat. 9286 S), anti-p53 (Santa Cruz, Cat. sc-98), anti-p53 (Santa Cruz, Cat. sc-55476). Bound antibodies were detected with peroxidase-coupled secondary antibodies incubated for $1 \mathrm{~h}$ at room temperature and the ECL system.

IRE1 $\alpha$ oligomerization assay. TREX cells expressing IRE1 $\alpha$-3F6HGFP WT were obtained from Dr. Peter Walter at UCSF and were previously described ${ }^{13}$. TREX cells plated and treated with doxycycline $(500 \mathrm{ng} / \mathrm{mL}$ for $48 \mathrm{~h})$. Cells were treated with $\operatorname{Tm}(1 \mu \mathrm{g} / \mathrm{mL})$ or etoposide $(25 \mu \mathrm{M})$ for different times points and fixed with $4 \%$ paraformaldehyde for $30 \mathrm{~min}$. Nuclei were stained with Hoechst dye. Coverslips were mounted with Fluoromount $\mathrm{G}$ onto slides and visualized by confocal microscopy (Fluoview FV1000). The number and size of IRE1a foci was quantified using segmentation and particle analysis of Image J software.

In vitro oligomerization assay. In all, $0.5 \mu \mathrm{g}$ of the cytoplasmic domain of GSTtagged IRE1 $\alpha$ (Sino Biologicals) and $0.1 \mu \mathrm{g}$ of His tagged c-Abl (Carna Biosciences) were incubating and mixing for indicated time points, at $37^{\circ} \mathrm{C}$ in a heat block (300 rmp). Total reaction was prepared in $100 \mu \mathrm{L}$ of oligomerization assay buffer (50 mM Tris- $\mathrm{HCl} \mathrm{pH}$ 7.5, $100 \mathrm{mM} \mathrm{NaCl}, 5 \mathrm{mM} \mathrm{MnCl}$, $5 \mathrm{mM} \mathrm{MgCl} 2,1 \mathrm{~mm}$ DTT $1 \mathrm{mM}$ ATP). The half of the reaction mixture was mixed with NuPAGE LDS sample buffer (Invitrogen) and loaded on 6\% denaturing polyacrylamide gel and subsequently analyzed by western blot.

Indirect Immunofluorescence. IRE1 $\alpha-\mathrm{HA}$, and $\gamma$-H2AX proteins were visualized by immunofluorescence. Cells were fixed for $30 \mathrm{~min}$ with $4 \%$ paraformaldehyde and permeabilized $0.5 \% \mathrm{NP}-40$ in PBS containing 0.5\% BSA (bovine serum albumin) for $10 \mathrm{~min}$. After blocking for $1 \mathrm{~h}$ with $10 \%$ FBS in PBS containing $0.5 \%$ BSA, cells were subsequently incubated with anti-HA 1:1000 (Invitrogen, Cat. 715500), anti-phosphorylated-Chk1, Ser348 1:1000 (Cell Signaling, Cat. 2341), anti-cleaved caspase 3, Asp175 1: (Cell Signalling, Cat. 9661) or anti-

Phosphorylated S139-H2AX 1:5000 (Millipore, Cat. 05-636) antibodies overnight at $4{ }^{\circ} \mathrm{C}$. Cell were washed three times in PBS containing $0.5 \%$ BSA, and incubated with Alexa-conjugated secondary antibodies (Molecular Probes) for $1 \mathrm{~h}$ at $37^{\circ} \mathrm{C}$. Nuclei were stained with Hoechst dye. Coverslips were mounted with Fluoromount $\mathrm{G}$ onto slides and visualized by confocal microscopy (Fluoview FV1000).

Automated microscopy. Cells were seeded in 96-well imaging plates (BD Falcon, Sparks, USA) $24 \mathrm{~h}$ before stimulation. Cells were treated with the indicated agents. Subsequently, cells were fixed with $4 \%$ PFA and counterstained with $10 \mu \mathrm{M}$ Hoechst 33342. After blocking for $1 \mathrm{~h}$ with $10 \%$ FBS in PBS containing $0.5 \%$ BSA, cells were subsequently incubated with anti-phosphorylated-Chk1, Ser345 1:1000 (Cell Signaling, Cat. 2348) antibody, overnight at $4{ }^{\circ} \mathrm{C}$. Cell were washed three times in PBS, and incubated with Alexa-conjugated secondary antibodies (Molecular Probes) for $1 \mathrm{~h}$ at $37^{\circ} \mathrm{C}$. Images were acquired using an ImageXpress Micro XLS Widefield High-Content Analysis System operated by the MetaXpress ${ }^{\circledast}$ Image Acquisition and Analysis Software (Molecular Devices, Sunnyvale, CA, US). Acquisition was performed by means of a 20X PlanApo objective (Nikon, Tokyo, Japan). Minium 9 views fields per well for 96-wells plate were acquired. MetaXpress $^{\circledR}$ was utilised to segment cells into nuclear area (based on Hoechst 33342 signal). Cell-like objects were segmented and divided into cytoplasmic and nuclear regions as previously reported ${ }^{49}$.

Proximity ligation assay (PLA). Cells were seeded in $12 \mathrm{~mm}$ cover slips. After the indicated treatments, cells were fixed for $20 \mathrm{~min}$ at RT with $4 \%$ paraformaldehyde and permeabilized $0.5 \%$ NP-40 in PBS containing 0.5\% BSA (Bovine serum albumin) for $10 \mathrm{~min}$. After blocking for $1 \mathrm{~h}$ with $10 \%$ FBS in PBS containing $0.5 \%$ BSA, cells were incubated with the indicated antibodies: Anti-HA (Cat: 901514, Biolegend or Cat: 9110, Abcam) and anti-Abl 1:1000 (Sigma, Cat. A5844) overnight at $4{ }^{\circ} \mathrm{C}$ following by Duolink manufacturer's instructions (Duolink ${ }^{\circledast}$, SigmaAldrich). Images were acquired by confocal microscopy (Nikon C2 plus) using a $60 \mathrm{X}$ oil objective lens stacking the images every $0.5 \mu \mathrm{m}$ to cover all the image of interest. Stack images were deconvoluted using Huygens and ImageJ. Stack deconvolved images were reduced to one dimension by sumslices function (ImageJ). Colocalization was performed in thresholded and masked images were used to determine Manders/Pearson's index was calculated with ImageJ plugin. 
Comet assay. The comet assay was performed as previously described ${ }^{50}$. Briefly, agarose-slides were prepared with $1 \%$ low-gelling-temperature agarose and $2 \times 10^{4}$ cells/ml and submerged in lysis solution (1.2 M NaCl, $100 \mathrm{mM} \mathrm{Na} \mathrm{m}_{2}$-EDTA, $0.1 \%$ sodium lauryl sarcosinate, $0.26 \mathrm{M} \mathrm{NaOH}(\mathrm{pH}>13)$ ) for $18 \mathrm{~h}$ at $4{ }^{\circ} \mathrm{C}$ in the dark Then, carefully slides removed and submerged in room temperature $\left(18-25^{\circ} \mathrm{C}\right)$ in rinse solution $\left(0.03 \mathrm{M} \mathrm{NaOH}, 2 \mathrm{mM} \mathrm{Na}_{2}\right.$ EDTA $(\mathrm{pH} \sim 12.3)$ ) for $20 \mathrm{~min}$. electrophoresis was conducted in the same solution for $25 \mathrm{~min}$ at a voltage of $0.6 \mathrm{~V} / \mathrm{cm}$. Finally, slides were stained in a solution containing $2.5 \mu \mathrm{g} / \mathrm{ml}$ of propidium iodide in distilled water for $20 \mathrm{~min}$ and observed in a epifluorescence microscopy. Images were analyzed using Comet Assay IV software.

Cytokinesis-block micronucleus assay. Cytokinesis-block micronucleus (CBMN) assay was performed as previously described ${ }^{51}$. In brief, cells were treated with 5 etoposide $(5 \mu \mathrm{M}$ for $3 \mathrm{~h})$. Then, cells were washed three times with PBS and incubated for $24 \mathrm{~h}$ with fresh media with $5 \mu \mathrm{M}$ of Cytochalasin-B. Cells were fixed, stained with Hoeschst. Binucleated cells (BN) with micronucleus (MN), Nuclear buds (Nbuds) or nucleoplasmid bridges (NPB) were detected and quantified using epifluorescence microscopy.

In vitro RNA cleavage assay. Bloc1s1 (NM_001487.3), Ppp2r1a (NM_014225) and RuvbL1 (NM_00370) cDNA were obtained from MGC cDNA library (Dharmacon). Long sense and antisense oligonucleotides containing a minimal T7 RNA polymerase promoter (5'-TAATACGACTCACTATAGG-3') fused upstream of the sequence containing different fragments of the genes Ppp2rla, RuvbL1 and Blocls1 harboring $5^{\prime}$-EcoRI and $3^{\prime}$-BamHI overhangs were annealed and ligated into the cognate restriction sites of pUC19 (Invitrogen, Life Technologies). Oligonucleotides sequence to clone Ppp2rla and RuvbL1 fragments were described previously ${ }^{20}$. In vitro transcription reactions were performed with T7 RNA polymerase using the HiScribe T7 high-yield RNA synthesis kit (New England Biolabs) following the manufacturer's recommendations. The transcribed RNA were treated for $20 \mathrm{~min}$ with DNase and purified by urea-polyacrylamide gel electrophoresis (urea-PAGE). RNAs recovered from gel fragments by the crush-and-soak method, were precipitated with $300 \mathrm{mM} \mathrm{NaOAc}$ and 1 volume of isopropanol. No coprecipitants were employed. The precipitated RNA pellets were desalted by two washes with $70 \%$ ice-cold ethanol, air-dried and re-suspended in an appropriate volume of either nuclease-free water or RNA resuspension buffer (20 mM HEPES, $\left.100 \mathrm{mM} \mathrm{NaCl}, 1 \mathrm{mM} \mathrm{Mg}(\mathrm{OAc})_{2}\right)$. The oligonucleotides sequence used are listed in the Supplementary Table 2.

The cytosolic kinase/ribonuclease domain construct of IRE1 $\alpha$ (KR43) was expressed and purified as described previously ${ }^{52}$. In vitro transcribed, PAGEpurified, refolded RNAs (50 ng) were incubated with $0.5 \mu \mathrm{M}$ IRE1 $\alpha$-KR43 for the indicated times in RNA cleavage buffer $(20 \mathrm{mM}$ HEPES pH $7.5,70 \mathrm{mM} \mathrm{NaCl}$ $2 \mathrm{mM} \mathrm{Mg}(\mathrm{OAc}), 1 \mathrm{mM}$ TCEP, and $5 \%$ glycerol). Stop solution (10 M urea, $0.1 \%$ SDS, $1 \mathrm{mM}$ EDTA, $0.05 \%$ xylene cyanol, $0.05 \%$ bromophenol blue) was added at five-fold excess to stop the reactions followed by heating at $80^{\circ} \mathrm{C}$ for $3 \mathrm{~min}$. The denatured samples were then loaded on $6 \%$ TBE-urea gels (Invitrogen, Life Technologies) and the gels stained with SYBR Gold nucleic acid stain (Invitrogen, Life Technologies). As a negative control we utilized the IRE1 $\alpha$ inhibitor $4 \mu 8 \mathrm{C}$ to a final concentration of $5 \mu \mathrm{M}$.

Viability assay. In all, $2.0 \times 10^{4}$ cells were seeded in 48 -well plate and the maintained by $24 \mathrm{~h}$ in DMEM cell culture media supplemented with $5 \%$ bovine fetal serum and non-essential amino acids. Genotoxic and ER stress were induced by adding genotoxic and ER stress agents to the cells at different concentrations, and maintained for $24 \mathrm{~h}$. Then, cell viability was monitored using propidium iodide staining and flow cytometry (BD FACS Canto, Biosciences).

Mouse model. Ern1 floxed mice were previously described ${ }^{53}$ and crossed with $\mathrm{Mx1-cre} \mathrm{transgenic} \mathrm{mice} \mathrm{to} \mathrm{generate} \mathrm{a} \mathrm{conditional} \mathrm{KO} \mathrm{animal} \mathrm{(IRE1} \alpha^{\mathrm{cKO}}$ ). Deletion was induced by injection of polyinosinic-polycytidylic acid (Poly (I:C)) which efficiently delete the floxed gene in the liver and bone marrow ${ }^{29}$. I all, 5-6-weeksold mice were intraperitoneally (i.p) injected three times with $250 \mu \mathrm{g}$ of poly(I:C) each time with 2 day intervals to induce the Cre expression. Mice were used for experiments at least 2-3 weeks after the final poly (I:C) injection. DMSO or $50 \mathrm{mg} /$ $\mathrm{Kg}$ etoposide or $1 \mathrm{mg} / \mathrm{Kg}$ tunicamycin or were i.p. injected and $6 \mathrm{~h}$ later mice were sacrificed as reported ${ }^{54}$. The liver and bone marrow were frozen at $-80{ }^{\circ} \mathrm{C}$ for biochemical analysis and the right major lobe of the liver was placed in a petri dish (on ice). Liver tissue was washed in PBS to remove the blood and then, it was fixed in $4 \%$ paraformaldehyde $(72 \mathrm{~h})$ for histological analyses. The animals' works and care was in accordance with institutional guidelines. Institutional Committee for Animal Care and Handling, University of Chile (Protocol CICUA-CBA-0833).

Fly studies. Flies were kept at $25^{\circ} \mathrm{C}$ on standard medium with a $12-12$ dark-light cycle. Drug administration protocol for all experiments is as follows: Larvae were grown in standard fly medium until day 3 after egg lying (AEL). Then they were transferred to fly instant medium (Carolina Biological Supply 2700 York Burlington, NC, USA) complemented with the appropriate drug for the different treatments. Larvae were fed with the corresponding drug-supplemented media until dissection or adulthood.
The UAS-Ire1 IR (v39562) line was obtained from the Vienna Drosophila RNAi Center (VDRC). The following lines were obtained from Bloomington Drosophila Stock Center (BDSC): UAS-GFP IR (BL-44412); Ire1 mutant w1118; PBac $\{\mathrm{WH}\}$ Ire ${ }^{\text {f02170}}$ /TM6B (BL-18520); mwh ${ }^{1}$ mutant (BL-549) and $\mathrm{flr}^{3} / \mathrm{TM} 3$, Ser stock (BL-2371). All fly strains are listed in the Supplementary Table 3.

SMART assay. For the SMART assay, larvae were fed in media complemented with $0.125 \mathrm{mg} / \mathrm{mL}$ Doxorubicin. Wings of the hatched female flies were fixed in ethanol, mounted in ethanol:lactic acid 1:1, and 15 wings per condition were analyzed at $\times 400$ magnification for the occurrence of mutant clones $(N=4)^{55}$.

Survival curve and biochemical analysis of fly tissue. Survival analyses were carried out growing 20 experimental or control larvae in $500 \mu \mathrm{M}$ etoposide and the number of living animals was quantified at different time points. For real time RTPCR analysis, total RNA was extracted from third instar larvae (same treatment as the survival analysis animals) using Trizol (Invitrogen, Carlsbad, CA, USA), and cDNA was synthesized with SuperScript III (Invitrogen) 56,57

For immunohistochemistry, larvae were fed with $0.125 \mathrm{mg} / \mathrm{mL}$ doxorubicin. Then third instar larvae were dissected and fixed as described previously ${ }^{58}$ Larvae carcasses were incubated with Anti-caspase-3 (1:100, Cell Signaling) overnight in PBT supplemented with $0.5 \%$ BSA at $4{ }^{\circ} \mathrm{C}$, washed four times with PBT for $15 \mathrm{~min}$ and stained with Alexa-conjugated secondary antibody (1:200, Molecular Probes) and TO-PRO3 ( $1 \mu \mathrm{M}$, Invitrogen). VectaShield (Vector Laboratories, Burlingame, California, USA) was used as a mounting media. The number of active Caspase- 3 positive cells was quantified in 10 wing imaginal $\operatorname{discs}(N=3)$. Images were taken using a Zeiss LSM510 confocal microscope and analyzed with ImageJ software.

Microarray analyses. Affymetrix gene expression data were pre-processed using Transcriptome Analysis Console (TAC) (v4.0, ThermoFisher Scientific). Custom mouse Brainarray chip definition (v22) was used to further annotate the DE files with Entrez and gene symbol IDs. For further analysis, just gene transcript with FDR $(a=0.05)$ correction and $1.5>$ fold change was considerated. For pathway enrichment analysis, data obtained from untreated wild type or IRE1 $\alpha^{\mathrm{cKO}}$ after poly I:C treatment liver mice tissues were used as reference for tunicamycin (Tm) and etoposide (Eto) treatment comparisons, to further input them in ClueGO (v2.3.2) software using Reactome pathway enrichment database (v09.11.2016). In addition, to visualize patterns in the gene expression and pathway enrichment scores for specific ontologies, heatmaps were generated using RStudio (v0.99.489, R 3.4.1) based on KEGG pathway database gene lists. Genes which show change of the ratios higher (or lower) than 1.5-fold in the arrays at any comparison have been considered as up or downregulated and subjected for functional enrichment analysis. The Bioconductor package 'clusterProfiler' was applied to perform functional enrichment analysis using the following repositories: GO (Gene Ontology), KEGG (Kyoto Encyclopedia of Genes and Genomes), and Reactome Pathways. GEO Dataset ID: GSE130952.

Statistical analysis. Results were statistically compared using the Ordinary Oneway ANOVA and Two-way ANOVA followed by different multiples comparison post-tests (Tukey's Multiple Comparison Test or Bonferroni's Multiple Comparison Test). When pertinent, Student's $t$-test was performed for unpaired or paired groups. In all plots $p$ values are show as indicated: $*: p<0.05,{ }^{*}: p<0.01$ $* * *: p<0.001$ and $* * * *: p<0.0001$ and were considered significant. n.s: nonsignificant.

Reporting summary. Further information on research design is available in the Nature Research Reporting Summary linked to this article.

\section{Data availability}

The source data underlying Figures and Supplementary Figures are provided as a Source Data file. All data is available from the corresponding author upon reasonable request.

Received: 18 April 2019; Accepted: 12 March 2020;

Published online: 14 May 2020

\section{References}

1. Pearl, L. H., Schierz, A. C., Ward, S. E., Al-lazikani, B. \& Pearl, F. M. G Therapeutic opportunities within the DNA damage response. Nat. Rev. Cancer 15, 166-180 (2015)

2. Chevet, E., Hetz, C. \& Samali, A. Endoplasmic reticulum stress-activated cell reprogramming in oncogenesis. Cancer Discov. 5, 586-597 (2016).

3. Cubillos-Ruiz, J. R., Bettigole, S. E. \& Glimcher, L. H. Tumorigenic and immunosuppressive effects of endoplasmic reticulum stress in cancer. Cell 168, 692-706 (2017). 
4. Walter, P. \& Ron, D. The unfolded protein response: from stress pathway to homeostatic regulation. Science 334, 1081-1086 (2011).

5. Hetz, C. \& Papa, F. R. The unfolded protein response and cell fate control. Mol. Cell. https://doi.org/10.1016/j.molcel.2017.06.017 (2018).

6. Urra, H., Dufey, E., Avril, T., Chevet, E. \& Hetz, C. Endoplasmic reticulum stress and the hallmarKS OF CAncer. Trends Cancer 2, 252-262 (2016).

7. Wang, M. \& Kaufman, R. J. Protein misfolding in the endoplasmic reticulum as a conduit to human disease. Nature 529, 326-335 (2016).

8. Hollien, J. \& Weissman, J. S. Decay of endoplasmic reticulum-localized mRNAs during the unfolded protein response. Science 313, 104-107 (2006).

9. Hollien, J. et al. Regulated Ire1-dependent decay of messenger RNAs in mammalian cells. J. Cell Biol. https://doi.org/10.1083/jcb.200903014 (2009).

10. Maurel, M., Chevet, E., Tavernier, J. \& Gerlo, S. Getting RIDD of RNA: IRE1 in cell fate regulation. Trends Biochem. Sci. 39, 245-254 (2014).

11. Han, D. et al. IRE1alpha kinase activation modes control alternate endoribonuclease outputs to determine divergent cell fates. Cell 138, 562-575 (2009).

12. Acosta-Alvear, D. et al. XBP1 controls diverse cell type- and condition-specific transcriptional regulatory networks. Mol. Cell 27, 53-66 (2007).

13. Li, H., Korennykh, A. V., Behrman, S. L. \& Walter, P. Mammalian endoplasmic reticulum stress sensor IRE1 signals by dynamic clustering. Proc. Natl Acad. Sci. USA 107, 16113-16118 (2010).

14. Carreras-Sureda, A. et al. Non-canonical function of IREla determines mitochondria-associated endoplasmic reticulum composition to control calcium transfer and bioenergetics. Nat. Cell Biol. 21, 755-767 (2019).

15. Sepulveda, D. et al. Interactome screening identifies the ER luminal chaperone Hsp47 as a regulator of the unfolded protein response transducer IRE1 $\alpha$. Mol. Cell 69, 238-251.e8 (2018).

16. Cross, B. C. S. et al. The molecular basis for selective inhibition of unconventional mRNA splicing by an IRE1-binding small molecule. Proc. Natl Acad. Sci. USA 109, E869-E878 (2012).

17. Burgess, R. C. \& Misteli, T. Not all DDRs are created equal: non-canonical DNA damage responses. Cell 162, 944-947 (2015).

18. Kitagawa, R., Bakkenist, C. J., McKinnon, P. J. \& Kastan, M. B. Phosphorylation of SMC1 is a critical downstream event in the ATM-NBS1BRCA1 pathway. Genes Dev. https://doi.org/10.1101/gad.1200304 (2004).

19. White, D. et al. The ATM substrate KAP1 controls DNA repair in heterochromatin: Regulation by HP1 proteins and serine $473 / 824$ phosphorylation. Mol. Cancer Res. https://doi.org/10.1158/1541-7786.MCR11-0134 (2012)

20. Hur, K. Y. et al. IRE1 a activation protects mice against acetaminopheninduced hepatotoxicity. J. Exp. Med. 209, 307-318 (2012)

21. Oikawa, D., Tokuda, M., Hosoda, A. \& Iwawaki, T. Identification of a consensus element recognized and cleaved by IRE1a. Nucleic Acids Res. 38, 6265-6273 (2010).

22. Chowdhury, D. et al. $\gamma-\mathrm{H} 2 \mathrm{AX}$ dephosphorylation by protein phosphatase $2 \mathrm{~A}$ facilitates DNA double-strand break repair. Mol. Cell 20, 801-809 (2005).

23. Jha, S., Shibata, E. \& Dutta, A. Human Rvb1/Tip49 is required for the histone acetyltransferase activity of Tip60/NuA4 and for the downregulation of phosphorylation on H2AX after DNA damage. Mol. Cell. Biol. 28, 2690-2700 (2008).

24. Hetz, C., Chevet, E. \& Oakes, S. A. Proteostasis control by the unfolded protein response. Nat. Cell Biol. 17, 829-838 (2015).

25. Urra, H. et al. IRE1 $\alpha$ governs cytoskeleton remodelling and cell migration through a direct interaction with filamin A. Nat. Cell Biol. 20, 942-953 (2018).

26. Morita, S. et al. Targeting ABL-IRE1 $\alpha$ signaling spares ER-stressed pancreatic $\beta$ cells to reverse autoimmune diabetes. Cell Metab. 25, 883-897. e8 (2017).

27. Greuber, E. K., Smith-Pearson, P., Wang, J. \& Pendergast, A. M. Role of ABL family kinases in cancer: from leukaemia to solid tumours. Nat. Rev. Cancer 13, 559-571 (2013).

28. Coelho, D. S. et al. Xbp1-Independent Ire1 signaling is required for photoreceptor differentiation and rhabdomere morphogenesis in Drosophila. Cell Rep. 5, 791-801 (2013).

29. Lee, A.-H., Scapa, E. F., Cohen, D. E. \& Glimcher, L. H. Regulation of hepatic lipogenesis by the transcription factor XBP1. Science. https://doi.org/10.1126/ science.1158042 (2008).

30. Lee, J. H. et al. ATM directs DNA damage responses and proteostasis via genetically separable pathways. Sci. Signal. 11, 1-18 (2018).

31. Edifizi, D. et al. Multilayered reprogramming in response to persistent DNA damage in C. elegans. Cell Rep. 20, 2026-2043 (2017).

32. Gomes-da-Silva, L. C. et al. Photodynamic therapy with redaporfin targets the endoplasmic reticulum and Golgi apparatus. EMBO J. 37, e98354 (2018).

33. Zheng, P. et al. DNA damage triggers tubular endoplasmic reticulum extension to promote apoptosis by facilitating ER-mitochondria signaling. Cell Res. 28, 833-854 (2018).
34. Cabrera, E. et al. PERK inhibits DNA replication during the unfolded protein response via Claspin and Chk1. Oncogene 36, 678-686 (2017).

35. Weatherbee, J. L. et al. ER stress in temozolomide-treated glioblastomas interferes with DNA repair and induces apoptosis. Oncotarget 7, 43820-43834 (2016).

36. Oommen, D. \& Prise, K. M. Down-regulation of PERK enhances resistance to ionizing radiation. Biochem. Biophys. Res. Commun. 441, 31-35 (2013).

37. Yamamori, T., Meike, S., Nagane, M., Yasui, H. \& Inanami, O. ER stress suppresses DNA double-strand break repair and sensitizes tumor cells to ionizing radiation by stimulating proteasomal degradation of Rad51. FEBS Lett. 587, 3348-3353 (2013).

38. Bobrovnikova-Marjon, E. et al. PERK promotes cancer cell proliferation and tumor growth by limiting oxidative DNA damage. Oncogene 29, 3881-3895 (2010).

39. Huang, C. et al. Identification of XBP1-u as a novel regulator of the MDM2/ p53 axis using an shRNA library. Sci. Adv. https://doi.org/10.1126/ sciadv.1701383 (2017)

40. Lhomond, S. et al. Dual IRE1 RNase functions dictate glioblastoma development. EMBO Mol. Med. 10, e7929 (2018).

41. Pluquet, O. et al. Posttranscriptional regulation of perl underlies the oncogenic function of IREa. Cancer Res. https://doi.org/10.1158/0008-5472. CAN-12-3989 (2013)

42. Tavernier, S. J. et al. Regulated IRE1-dependent mRNA decay sets the threshold for dendritic cell survival. Nat. Cell Biol. 19, 698-710 (2017).

43. Osorio, F. et al. The unfolded-protein-response sensor IRE-1 $\alpha$ regulates the function of CD8a+ dendritic cells. Nat. Immunol. 15, 248-257 (2014).

44. Lerner, A. G. et al. IRE1a induces thioredoxin-interacting protein to activate the NLRP3 inflammasome and promote programmed cell death under irremediable ER stress. Cell Metab. 16, 250-264 (2012).

45. Greenman, C. et al. Patterns of somatic mutation in human cancer genomes Nature 446, 153-158 (2007).

46. Hetz, C. et al. Proapoptotic BAX and BAK modulate the unfolded protein response by a direct interaction with IRE1alpha. Science 312, 572-576 (2006).

47. Rodriguez, D. A. et al. BH3-only proteins are part of a regulatory network that control the sustained signalling of the unfolded protein response sensor IRE1a. EMBO J. 31, 2322-2335 (2012).

48. Lisbona, F. et al. BAX Inhibitor-1 is a negative regulator of the ER stress sensor IRE1a. Mol. Cell. https://doi.org/10.1016/j.molcel.2009.02.017 (2009).

49. Bravo-San Pedro, J. M., Kroemer, G. \& Galluzzi, L. Autophagy and mitophagy in cardiovascular disease. Circ. Res. https://doi.org/10.1161/ CIRCRESAHA.117.311082 (2017).

50. Olive, P. L. \& Banáth, J. P. The comet assay: a method to measure DNA damage in individual cells. Nat. Protoc. 1, 23-29 (2006).

51. Fenech, M. Cytokinesis-block micronucleus cytome assay in lymphocytes. Nat. Protoc. 2, 1084-1104 (2007).

52. Mendez, A. S. et al. Endoplasmic reticulum stress-independent activation of unfolded protein response kinases by a small molecule ATP-mimic. Elife $\mathbf{4}$, $1-27$ (2015)

53. Iwawaki, T., Akai, R., Yamanaka, S. \& Kohno, K. Function of IRE1 alpha in the placenta is essential for placental development and embryonic viability. Proc. Natl Acad. Sci. USA https://doi.org/10.1073/pnas.0903775106 (2009).

54. Nakama, T. et al. Etoposide prevents apoptosis in mouse liver with DGalactosamine/lipopolysaccharide-induced fulminant hepatic failure resulting in reduction of lethality. Hepatology 33, 1441-1450 (2001).

55. Graf, U. et al. Somatic mutation and recombination test in Drosophila melanogaster. Environ. Mutagen. 6, 153-188 (1984).

56. Castillo, K. et al. BAX inhibitor-1 regulates autophagy by controlling the IRE1a branch of the unfolded protein response. EMBO J. 30, 4465-4478 (2011).

57. Rojas-Rivera, D. et al. TMBIM3/GRINA is a novel unfolded protein response (UPR) target gene that controls apoptosis through the modulation of ER calcium homeostasis. Cell Death Differ. 19, 1013-1026 (2012).

58. Cruz, C., Glavic, A., Casado, M. \& De Celis, J. F. A gain-of-function screen identifying genes required for growth and pattern formation of the Drosophila melanogaster wing. Genetics 183, 1005-1026 (2009).

\section{Acknowledgements}

We thank Dr. Takao Iwawaki for providing IRE1 flox mice. We Thank Dr. David Ron for providing IRE1 null MEFs. We thank Dr. Alexis Rivas for assistance with Cellomics array scan (FONDEQUIP EQM120164). We thank Javiera Ponce for assistance with animal care. ANID/FONDAP program 15150012, Millennium Institute P09-015-F, CONICYTBrazil 441921/2016-7, FONDEF ID16I10223, FONDEF D11E1007, and FONDECYT 1180186 (C.H.), and Ecos-Conicyt ${ }^{\circ}$ C17S02 (C.H.). In addition, we thank the support from the U.S. Air Force Office of Scientific Research FA9550-16-1-0384, and Muscular Dystrophy Association, US Office of Naval Research-Global (ONR-G) N62909-16-12003, and the European Commission R\&D MSCA-RISE-734749 (INSPIRED). We thank the support from: FONDECYT 11180825 (H.U.); FONDECYT 3190738 (A.I.S.); 
FONDECYT 3180427 (Y.H.), FONDECYT 3150113 (A.C.-S.), and EMBO ASTF 3852016 (A.C.-S.); CONICYT fellowship (PCHA/Doctorado Nacional/2016-21160232) (M.G.-Q.), MSCA RISE-734749 (INSPIRED) (M.Q.-G.) and FONDAP-GERO-15150012 (A.I.S., P.P.). A.G. is supported by FONDAP-CRG-15090007 and ACT1401. DAA was supported by an Irvington Postdoctoral Fellowship of the Cancer Research Institute. A.A. is supported by FONDECYT 1161065 and AFB170005. G.K. is supported by the Ligue contre le Cancer (équipe labellisée); Agence National de la Recherche (ANR)-Projets blancs; ANR under the frame of E-Rare-2, the ERA-Net for Research on Rare Diseases; Association pour la recherche sur le cancer (ARC); Cancéropôle Ile-de-France; Chancelerie des universités de Paris (Legs Poix), Fondation pour la Recherche Médicale (FRM); a donation by Elior; the European Commission (ArtForce); European Research Area Network on Cardiovascular Diseases (ERA-CVD, MINOTAUR); the European Research Council (ERC); Fondation Carrefour; Institut National du Cancer (INCa); Inserm (HTE); Institut Universitaire de France; LeDucq Foundation; the LabEx Immuno-Oncology; the RHU Torino Lumière; the Seerave Foundation; the SIRIC Stratified Oncology Cell DNA Repair and Tumor Immune Elimination (SOCRATE); the SIRIC Cancer Research and Personalized Medicine (CARPEM); and the Paris Alliance of Cancer Research Institutes (PACRI). P.M.D was supported by FCT LISBOA-01-0145FEDER-007660, PTDC/NEU-NMC/2459/2014 and IF/00697/2014 (Portugal). R.P. is supported by Fondation pour la Recherche Médicale (FMR, DEQ20180339169) and Institut National de la Santé et de la Recherche Médicale (INSERM). E.C. is supported by Institut National du Cancer (INCa PLBIO), ANR under the frame of ERANET (ERAAT) and EU H2020 MSCA ITN-675448 (TRAINERS) and MSCA RISE-734749 (INSPIRED).

\section{Author contributions}

E.D., M.G-Q., and A.I.S.: conceived and designed the project, carried out experimental work with cell culture and mouse models, and wrote the paper; J.M.B., C.E., H.U., D.S., P.P., A.C.-S., Y.H., E.A.S., D.G., C.V., A.P., D.A.-A., G.C., P.G., A.G.: carried out experimental work and interpreted data; P.G. and E.A.S.: performed bioinformatics work, interpreted data and wrote the manuscript; A.A., P.M.D., Contributed to project design and data interpretation; C.H., P.W., G.K., R.P., E.C.: contributed to project design, interpreted data and wrote the paper.

\section{Competing interests}

The authors declare no competing interests.

\section{Additional information}

Supplementary information is available for this paper at https://doi.org/10.1038/s41467$020-15694-y$.

Correspondence and requests for materials should be addressed to C.H.

Peer review information Nature Communications thanks Martin Lavin, Hermann Steller and the other, anonymous, reviewer(s) for their contribution to the peer review of this work. Peer reviewer reports are available.

Reprints and permission information is available at http://www.nature.com/reprints

Publisher's note Springer Nature remains neutral with regard to jurisdictional claims in published maps and institutional affiliations.

Open Access This article is licensed under a Creative Commons Attribution 4.0 International License, which permits use, sharing, BY Attribution 4.0 International License, which permits use, sharing
adaptation, distribution and reproduction in any medium or format, as long as you give appropriate credit to the original author(s) and the source, provide a link to the Creative Commons license, and indicate if changes were made. The images or other third party material in this article are included in the article's Creative Commons license, unless indicated otherwise in a credit line to the material. If material is not included in the article's Creative Commons license and your intended use is not permitted by statutory regulation or exceeds the permitted use, you will need to obtain permission directly from the copyright holder. To view a copy of this license, visit http://creativecommons.org/ licenses/by/4.0\%

(C) The Author(s) 2020 